REYES, Italo. "Sobre la construcción de la exigencia de cuidado".

Polít. crim. Vol. 10, No 19 (Julio 2015), Art. 3, pp. 56-91.

[http://www.politicacriminal.cl/Vol_10/n_19/Vol10N19A3.pdf]

\title{
Sobre la construcción de la exigencia de cuidado
}

\section{About the construction of the duty of care}

\author{
Italo Reyes Romero \\ Investigador, Universidad de Chile \\ mdpinvestiga@derecho.uchile.cl
}

\begin{abstract}
Resumen
El objetivo del artículo es explorar el contenido de la exigencia de cuidado como elemento medular de la imputación a título de imprudencia. Para ello, se fundamentan y defienden tres ideas: en primer lugar, se sostiene que tal exigencia de cuidado se construye en atención a un estándar objetivo, lo cual se opone a una culpa simplemente sicológica que observa una falla mental en el agente. En segundo lugar, que la noción de cuidado es siempre irrenunciable para la imprudencia, de manera que cualquier esfuerzo dogmático que la sustituya por la mera cognoscibilidad o previsibilidad del resultado típico es insuficiente. Y, finalmente, que es fundamental considerar los conocimientos y capacidades específicos del autor para determinar lo que resultaba cuidadoso según el contexto, negándose, por tanto, aquellas posiciones doctrinarias que se enfocan en los conocimientos y capacidades de un hombre abstracto promedio.
\end{abstract}

Palabras clave: Imprudencia, exigencia de cuidado, estándar objetivo, conocimientos especiales.

\begin{abstract}
The aim of the paper is to explore the content of the duty of care, which is the most important element of imputation by way of negligence. For this, the paper argues and defends three main ideas: First, these duties of care are constructed by an objective standard, which contradicts a mere psychological negligence that identifies a mental failure in the agent. Second, the notion of care is always inalienable, hence any dogmatic effort to change it by mere cognoscibility of the wrong is insufficient. And, finally, in order to define what the careful conduct according to context is, it is essential to take into consideration the specific knowledge and capacities of the subject, which denies those theories that focus in the knowledge and capacities of an abstract average man.
\end{abstract}

Key words: Negligence, duty of care, objective standard, special knowledge.

\section{Cuestión preliminar: la imputación a título de imprudencia}

Previo a discutir respecto de la manera en que debe ser construida la exigencia de cuidado, es necesario explicar el papel que ocupa tal exigencia en la verificación de un (cuasi)delito 
REYES, Italo. "Sobre la construcción de la exigencia de cuidado".

y, específicamente, en el esquema de imputación subjetiva. En términos generales, la imprudencia alude a la comprobación de que, si bien un sujeto no estaba capacitado para evitar una conducta que satisface la descripción típica, sí estaba capacitado para evitar tal situación de incapacidad. Para ello, le resultaba exigible adoptar medidas de precaución contextualmente pertinentes con el objeto de asegurar su capacidad de seguimiento futuro de la norma. En el resto de esta introducción, por tanto, se expondrá brevemente el modelo de imputación con el cual este artículo está comprometido, con la finalidad de contextualizar la discusión posterior sobre la exigencia de cuidado.

Entendiendo que el estudio de la imprudencia se enmarca en el injusto subjetivo, este trabajo pasa por alto la problemática de la imputación objetiva al entenderse que no es un asunto que influya en la determinación del contenido de la exigencia de cuidado. Sin embargo, basta señalar que la construcción aquí propuesta se complementa con la exclusión de todo juicio de imputación en el injusto objetivo, el cual se colma totalmente en un proceso de subsunción que permite aseverar que la conducta ejecutada por el sujeto es una forma particularizada de la descripción típica. Lo interesante está en que la inclusión de un filtro de imputación objetivo sólo podría llevar a uno de dos resultados, ninguno de ellos deseable: o bien que el filtro sea completamente superfluo pues no tiene efecto alguno en lo que se imputa subjetivamente, o bien que el filtro sea contraindicado pues obstaculiza aquello que hubiese resultado imputable subjetivamente ${ }^{1}$. En esos términos, no puede sino concluirse que tal filtro es un mal filtro.

Ahora bien, en el ámbito subjetivo del injusto, se estudian tradicionalmente los conceptos de dolo y de imprudencia. Sin embargo, lo que está detrás de ambas categorías es la posibilidad de atribuir la conducta que realiza la descripción típica a un determinado sujeto. Es decir, determinar si el autor contaba con las capacidades necesarias para el seguimiento de la norma, de modo que si contaba con ellas e igualmente ha ejecutado el comportamiento antinormativo, queda legitimado (en principio) un reproche en su contra. Sólo así es posible observar la contradicción entre la voluntad subjetiva del autor, objetivada en su comportamiento, y la voluntad general del ordenamiento.

Lo relevante es que el proceso de imputación se realiza en virtud de ciertos criterios o reglas que otorgan contenido a la respuesta punitiva por el comportamiento demeritorio y que varían respecto del ámbito de imputación ${ }^{2}$. Estos criterios de imputación aluden al reconocimiento de capacidades que permiten adscribir el comportamiento típico al sujeto.

La imputación básica u ordinaria ${ }^{3}$ revisa si el sujeto presenta las condiciones físicas e intelectuales (cognitivas) con las cuales podría haber evitado la comisión del hecho ${ }^{4}$. En la

\footnotetext{
${ }^{1}$ Para una crítica estructurada a la teoría de la imputación objetiva, véase KINDHÄUSER, Urs, "El tipo subjetivo en la construcción del delito", InDret 4/2008, pp. 13 y ss.

${ }^{2}$ HRUSCHKA, Joachim, "Reglas de comportamiento y reglas de imputación" en: EL MISMO, Imputación y Derecho Penal. Montevideo/Buenos Aires: B de F, 2009, pp. 14 y ss. Véase también, PÉREZ DEL VALLE, Carlos, La imprudencia en el derecho penal. El tipo subjetivo del delito imprudente, Barcelona: Atelier, 2012, pp. 143 y ss.

3 Véase HRUSCHKA, Joachim, "La imputación ordinaria y extraordinaria en Pufendorf", en: EL MISMO, su, Imputación y Derecho Penal, Montevideo/Buenos Aires: B de F, 2009, p. 55.
} 
Polít. crim. Vol. 10, No 19 (Julio 2015), Art. 3, pp. 56-91.

[http://www.politicacriminal.cl/Vol_10/n_19/Vol10N19A3.pdf]

medida que esas condiciones implican que el sujeto estuviese en posición física de actuar distinto y que además tuviese el conocimiento suficiente sobre las consecuencias de su actuar, aquí el criterio de imputación relevante es el dolo ${ }^{5}$. Entonces, quien se comporta dolosamente se encuentra en posición de actuar conforme a la norma de prohibición o de mandato respectiva, ya que le es evitable tanto física como cognitivamente su infracción, de manera que si ejecuta una acción que realiza la descripción típica está expresando con ello su negativa al seguimiento de la norma; en definitiva, una voluntad de negación del derecho.

Lo que nos interesa en esta investigación, no obstante, es lo que acontece cuando el sujeto carece de la capacidad necesaria para evitar la realización típica. Ello implica que el dolo queda descartado ya que, en el momento relevante, le era imposible ejecutar un comportamiento adecuado a deber. Empero, aún podemos preguntarnos por la razón por la cual el sujeto carece de la capacidad para evitar el resultado lesivo, es decir, por qué no hay dolo. La pregunta es interesante pues es posible desarrollar acciones que aseguren la capacidad futura, en el sentido que se pretenda evitar una situación de inevitabilidad. En otras palabras, quien asuma las normas penales como razones para la acción, no sólo puede interesarle evitar la ejecución de acciones que provoquen resultados típicos, sino también evitar una situación en la cual no podrá evitar ese resultado típico. De tal forma, el examen de esta "evitación de la inevitabilidad" se corresponde con el estudio de la imprudencia: el que actúa conforme a cuidado asegura su capacidad para evitar la infracción del deber ${ }^{6}$.

Por tanto, en el ámbito de la imprudencia, se determina que el sujeto es responsable por el hecho, no basado en la capacidad que tenía en el momento de su ejecución, sino por la capacidad que podría haber tenido si hubiese actuado previamente atendiendo al seguimiento futuro de la norma. En definitiva, se imputa que el sujeto no se hubiese

\footnotetext{
${ }^{4}$ MAÑALICH, Juan Pablo, "Norma e imputación como categorías del hecho punible", Revista de Estudios de la Justicia $\mathrm{n}^{\circ} 12$ (2010), pp. 179 y ss.

${ }^{5}$ KINDHÄUSER, Urs, “¿Qué es la imprudencia?”, en: MAÑALICH, Juan Pablo (Dir.), La ciencia penal en la Universidad de Chile. Libro homenaje a los profesores del departamento de ciencias penales de la facultad de Derecho de la Universidad de Chile, Santiago: Facultad de Derecho, Universidad de Chile, 2013, p. 220. Evidentemente una postura como la señalada asume una posición "cognitivista" del dolo. Para una revisión tradicional de las teorías al respecto, véase GARRIDO MONTT, Mario, Derecho Penal. Parte Especial, Tomo II, $4^{a}$ Ed., Santiago: Editorial Jurídica de Chile, 2005, pp. 78 y ss. Para una revisión más detallada, véase RAGUÉS I VALLES, Ramón, El dolo y su prueba en el proceso penal, Barcelona: Bosch Editor, 1999, pp. 189 y ss.

${ }^{6}$ En el mismo sentido, OVALLE, Germán, "Imprudencia y cognición”, Doctrina y jurisprudencia penal n ${ }^{\circ} 4$ (2011), p. 5. En un sentido similar, PÉREZ DEL VALLE, La imprudencia, cit. nota ${ }^{\circ} 2$, pp. 86 y ss., quien reconoce, por tanto, la radical importancia de la parte especial para un análisis adecuado de la imprudencia. Asumir esta posición implica entender que la imprudencia opera como imputación extraordinaria, es decir, como un proceso de atribución que sólo adquiere relevancia cuando la imputación ordinaria se ve excluida. Tal afirmación abarca tanto la imprudencia consciente como la inconsciente pues, para una imputación extraordinaria de primer nivel, lo relevante es que no se observe una representación de las circunstancias requerida para el dolo, la cual es de una entidad superior que la observada en la imprudencia consciente. Otro ejemplo de imputación extraordinaria está en los casos de actio libera in causa, en donde se excluye la imputación ordinaria de segundo nivel, o sea, respecto de la culpabilidad. Valga la advertencia que no se profundizará sobre los contornos y problemas de considerar a la imprudencia como forma de imputación extraordinaria pues la presente investigación está enfocada y circunscrita a la dilucidación del contenido de la exigencia de cuidado (y no en el significado de la imprudencia).
} 
REYES, Italo. "Sobre la construcción de la exigencia de cuidado".

comportado de la manera que evitaba esa incapacidad, es decir, de una manera que evitaría la afectación de bienes jurídicos a través de acciones futuras que escapasen a su control ${ }^{7}$.

Así entonces, en el contexto de la imprudencia, el criterio de imputación está constituido por la infracción de una exigencia de cuidado ${ }^{8}$, puesto que si el sujeto pretende mantener su capacidad de seguimiento futuro de la norma tiene que adoptar las medidas de cuidado pertinentes. En caso de no adoptar tales medidas, se justifica imputarle el comportamiento típico en cuestión teniéndose por configurado el injusto subjetivo. Lo que debe desentrañarse, entonces, es cómo se construye esa exigencia de cuidado o, en otras palabras, qué significa aseverar que alguien se ha comportado de modo imprudente.

\section{La exigencia de cuidado.}

Por supuesto, señalar de partida que esta investigación trata sobre el contenido de la exigencia de cuidado implica prejuzgar algunas de las respuestas a la pregunta acerca de cómo determinamos que alguien se ha comportado de modo imprudente. Hablar ya de una exigencia de cuidado no es, en modo alguno, neutral sino que asume una determinada posición que requiere ser clarificada y perfeccionada. Entonces, es preciso conocer de inmediato la premisa que será desarrollada en los próximos capítulos, a saber: la imprudencia se construye de acuerdo a un estándar objetivo (1) de cuidado (2) que incorpora los conocimientos y capacidades del sujeto (3). Ya referirse al concepto de exigencia de cuidado presupone haber asumido una postura respecto a las dos primeras temáticas.

En lo que sigue, se desarrollarán los elementos de la premisa -que quedan indicados con los números respectivos- lo cual implica tanto fundar dogmáticamente tales ideas como además refutar la posición contraria. Valga un breve anticipo a modo introductorio: en primer lugar, es fundamental que la exigencia de cuidado se entienda como un estándar objetivo, de modo que lo exigido sea igual para todo destinatario. Ello implica, por tanto, oponerse a una concepción de imprudencia puramente sicológica que pretende encontrar una falla mental en la acción imprudente. En segundo lugar, para determinar lo que un sujeto debe hacer para asegurar su capacidad futura no es posible renunciar, en modo alguno, al concepto de cuidado. De tal modo, los esfuerzos dogmáticos por centrar el análisis solamente en el concepto de cognoscibilidad o previsibilidad deben ser rechazados por insuficientes. Y en tercer lugar, con el objetivo de comprobar que el autor se ha comportado de modo imprudente, es necesario incorporar sus conocimientos y capacidades en el análisis de la exigencia de cuidado. Por tanto, debe asumirse una postura individualizadora, la que contradice lo sostenido por las posturas generalizadoras, las cuales enfatizan la relevancia de una figura promedio abstracta por sobre el individuo específico que se trata de imputar.

\footnotetext{
${ }^{7}$ Esto supone entender que dolo e imprudencia aluden a criterios cualitativamente diferenciados ya que se corresponden con formas conceptualmente diferentes de imputación. En contra de una diferencia cualitativa y a favor de una diferencia meramente cuantitativa, véase MOLINA, Fernando, "Dolo eventual e imprudencia con representación en los delitos de tránsito", Doctrina y jurisprudencia penal n 6 (2011), pp. 4 y ss.

${ }^{8}$ Se preferirá utilizar exigencia de cuidado antes que, la nomenclatura más frecuente de, deber de cuidado, puesto que sólo la primera es neutral respecto de la necesidad lógica (o no) de la obligación de cuidado.
} 
Polít. crim. Vol. 10, No 19 (Julio 2015), Art. 3, pp. 56-91.

[http://www.politicacriminal.cl/Vol_10/n_19/Vol10N19A3.pdf]

\section{La exigencia de cuidado como un estándar objetivo.}

En el derecho anglosajón, antes de la década de los setenta, existían posiciones que asumían una perspectiva estrictamente sicológica de la imprudencia. Una de ellas era la sostenida por James Turner ${ }^{9}$, quien afirmaba que la sanción por imprudencia implicaba una responsabilidad estricta $u$ objetiva que prescinde de cualquier elemento subjetivo en la configuración del delito. Ello porque el presupuesto para la sanción penal, en su opinión, es que el autor "tenga en su mente" la idea de dañar a otro. Si la negligencia, entonces, es entendida como "el estado mental de un hombre que emprende un comportamiento sin advertir en absoluto sus consecuencias" "resulta evidente que el autor "no tiene en su mente" la idea de dañar a otro, no cumpliéndose el mencionado requisito. Una sanción por un delito imprudente, entonces, conllevaría un problema serio de fundamentación puesto que se castigaría la no tenencia de la idea de quebrantar el derecho, o sea, se estaría configurando responsabilidad penal simplemente en atención a un espacio mental en blanco (a mere blank) ${ }^{11}$ : la inadvertencia de las consecuencias de una acción carece de repercusión mental y, por tanto, no puede ser capaz de fundamentar una pena. En base a ello, la configuración de delitos imprudentes escaparía al reconocimiento de elementos subjetivos - no hay nada en la mente del sujeto pues su relación con el resultado típico consiste simplemente en no advertir esas consecuencias perjudiciales- requiriéndose la afirmación de responsabilidad objetiva en todos esos casos. De tal forma, la idea de Turner es que, bajo un modelo sicológico radical, el delito imprudente no conllevaría una responsabilidad penal ligada a un principio de merecimiento (culpabilidad) sino más bien una responsabilidad estricta u objetiva.

En el contexto del derecho continental, por su parte, la importancia de los elementos sicológicos en la descripción de la imprudencia se ha visto atenuada por la constante presencia de elementos normativos, sin conocerse -al menos para este autor- modelos radicalmente sicológicos como el de Turner $^{12}$. No obstante, es posible reconocer planteamientos que otorgan preeminencia a elementos de índole sicológico, al exigir una revisión de lo que sucedía "en la mente" del autor para construir la noción de imprudencia. Así podríamos identificar dos modelos generales que dan importancia a elementos sicológicos diferentes: por una parte, un modelo del entendimiento, en el cual el delito imprudente se reconoce en atención al desconocimiento del autor del comportamiento y sus consecuencias $^{13}$; y, por otra parte, un modelo de la voluntad, el cual entiende que la imprudencia se caracteriza porque el autor quiere la acción, pero no quiere el resultado

\footnotetext{
9 TURNER, James, "The mental elements in crimes at common law", The Modern Approach of Criminal Law, citado en: HART, H.L.A, "Negligence, mens rea and criminal responsibility", en su Punishment and Responsibility, Oxford: Oxford University Press, 2008, p. 138.

${ }^{10}$ Traducido directamente de la cita explícita en HART, "Negligence", cit. nota no 9, p. 146.

${ }^{11}$ HART, "Negligence", cit. nota ${ }^{\circ}$ 9, p. 147.

${ }^{12}$ Más aún, con la popularización del concepto del deber de cuidado por Engisch en la primera mitad del siglo pasado, la discusión ha estado enfocada desde entonces en desentrañar el contenido de este concepto primariamente normativo. Véase infra capítulo 2.

${ }^{13}$ PÉREZ DEL VALLE, La imprudencia, cit. nota ${ }^{\circ}$ 2, p. 39. Ésta sería la interpretación más o menos dominante en la doctrina penal española de mediados del siglo XIX en referencia al código penal de 1822 y sus proyectos de modificación posteriores. En sentido similar, CORCOY, Mirentxu, El delito imprudente, Montevideo/Buenos Aires: B de F, 2005, pp. 45 y ss.
} 
REYES, Italo. "Sobre la construcción de la exigencia de cuidado".

efectivamente acaecido $^{14}$, de manera que manifiesta un ánimo de rechazo en su contra. Téngase claro que la comprensión de ambos modelos como moderadamente sicológicos no implica que éstos excluyan todo elemento normativo del análisis. Así, por ejemplo, el modelo del entendimiento no descansa simplemente en una dicotomía conocimientodesconocimiento sino que incorpora variables objetivas en la forma de una deber de previsibildad; y el modelo de la voluntad diferencia un ámbito objetivo del delito imprudente donde ubica al deber (normativo) de cuidado y uno subjetivo donde incluye el requisito del no-querer ${ }^{15}$. Sin embargo, esta clasificación resulta útil para evidenciar la primacía de un concepto sicológico distinto en ambos modelos y, asimismo, mostrarlos como moderados en comparación con la postura sicológica radical de Turner.

Contra el modelo sicológico radical de Turner, H.L.A. Hart sostiene que existe una confusión conceptual entre las nociones de inadvertencia y negligencia ${ }^{16}$. Si no es posible diferenciar ambos conceptos, entonces es correcto que no hay nada que reprochar al sujeto por el solo hecho de no advertir las consecuencias desafortunadas de su comportamiento. No obstante, lo que entendemos por un actuar imprudente, plantea Hart, no apunta al estado mental que tenía el sujeto al momento de ejecutar la conducta sino más bien a que éste ha fallado en respetar un estándar de precaución al cual estaba obligado en atención a las circunstancias de su acción ${ }^{17}$. En tal sentido, la afirmación de negligencia no tiene que ver con lo que sucede en la mente del sujeto sino con el cumplimiento (o no) de las medidas de precaución al cual éste estaba obligado para evitar daño a otros. Este planteamiento no afecta la idea de que el sujeto, al momento de realizar el comportamiento, no advirtiese las posibles consecuencias perjudiciales, pero tal "vacío mental" carece de repercusión en la afirmación o la negación de la imprudencia. Luego, "la negligencia no es el estado mental, mientras que la inadvertencia sí lo es" ${ }^{\prime 18}$.

Lo interesante del argumento de Hart es que explicita lo relevante que resulta acudir a un estándar para afirmar que alguien se ha comportado de manera imprudente. Si entendemos que la imprudencia analiza la capacidad de evitar una situación en la cual el sujeto no podrá controlar su conducta en la evitación un comportamiento típico, ésta se ve verificada cuando no se adoptan las medidas de precaución exigibles según la situación, sin interesar el estado mental del sujeto. Esto no quiere decir que los conocimientos del autor sean completamente inútiles para la determinación de lo que resultaba cuidadoso, sino que la presencia o ausencia de esos conocimientos no permite fundamentar (por sí sola) la imprudencia. De tal forma, la capacidad que observa la imprudencia no queda al arbitrio del autor sino que asume la forma de un estándar objetivo, como exigencia de cuidado, que mantiene la igualdad de todo integrante de la sociedad ${ }^{19}$. Esto porque el derecho penal

\footnotetext{
${ }^{14}$ PÉREZ DEL VALLE, La imprudencia, cit. nota $\mathrm{n}^{\text {o }}$ 2, p. 44. La posición que defiende la imputación como defecto de voluntad tiene raigambres filosóficas profundas que son analizadas con detalle en PÉREZ DEL VALLE, La imprudencia, cit. nota $\mathrm{n}^{\mathrm{o}} 2$, p. 44 y ss., pero que no son fundamentales para el objeto de esta investigación.

${ }^{15}$ PÉREZ DEL VALLE, La imprudencia, cit. nota ${ }^{\circ} 2$, pp. 41 y ss.

${ }^{16}$ HART, "Negligence", cit. nota ${ }^{\circ}$ 9, pp. 147 y ss.

${ }^{17}$ HART, "Negligence", cit. nota $\mathrm{n}^{\circ}$ 9, p. 148.

${ }^{18}$ HART, "Negligence", cit. nota $\mathrm{n}^{\circ}$ 9, p. 148.

${ }^{19}$ BINDING, Karl, La culpabilidad en derecho penal, Montevideo/Buenos Aires: B de F, 2009, p. 125.
} 
Polít. crim. Vol. 10, No 19 (Julio 2015), Art. 3, pp. 56-91.

[http://www.politicacriminal.cl/Vol_10/n_19/Vol10N19A3.pdf]

apunta a un ciudadano fiel a derecho, ya que las normas se dirigen con un mismo contenido para todos ${ }^{20}$.

En otras palabras, jurídicamente se determina el quantum de esfuerzo que los individuos deben emplear en la evitación de situaciones de inevitabilidad mediante una medida objetiva equivalente para todos ${ }^{21}$. Tal medida objetiva determina el cuidado necesario de una manera razonable, es decir, asumiendo que es imposible determinar estándares que prevengan todo riesgo de lesión de bienes jurídicos y, a la vez, permitan la ejecución de conductas socialmente beneficiosas ${ }^{22}$. Pero además, al ser la misma medida de cuidado para todos, los únicos elementos relevantes para fijar el cuidado exigible son el contexto y las capacidades del sujeto, de modo que no es posible diferenciar entre sujetos que tienen las mismas capacidades y están en la misma situación: el guardavía que está estresado por un conflicto con su pareja está sujeto a la misma exigencia de cuidado que aquel que no ha tenido conflicto alguno. A misma capacidad y mismas circunstancias de actuación, el nivel de esfuerzo que jurídicamente se exige para evitar resultados lesivos tiene que ser el mismo. Que la medida de cuidado dependiera concretamente del destinatario significaría criterios personalizados en el aseguramiento de capacidades posteriores, cuando lo exigible es igual para todos. Y tal equivalencia se logra mediante un estándar objetivo de cuidado.

Dos cuestiones vale la pena descifrar de inmediato. Es posible que la nomenclatura mayoritariamente utilizada de estándar objetivo pudiese implicar alguna conexión entre la imprudencia y un sistema de responsabilidad objetiva. Es decir, dado que el estándar es objetivo no habría elemento subjetivo que analizar, de manera que si alguien careciera de las capacidades que presupone el estándar igualmente sería afirmada su imprudencia e impuesta la pena correspondiente ${ }^{23}$. Ésa es una mala suposición porque lo único que se pretende al afirmar un estándar objetivo es que resulta necesaria una medida equivalente para la exigencia de cuidado de todos los sujetos. Ello no prejuzga, por tanto, sobre el contenido que le daremos al estándar y que distará de ser totalmente objetivo: la referencia siempre es a la capacidad del sujeto específico que ejecutó la conducta, de modo que la determinación de lo que resulta cuidadoso tiene que tomar en cuenta a ese sujeto ${ }^{24}$.

Y en segundo lugar, e inmediatamente ligado a lo anterior, tampoco atender a la capacidad del sujeto convierte en subjetiva la medida de cuidado ${ }^{25}$. El aparente problema surge al reconocer la necesidad de atender a las capacidades del autor específico para evitar una responsabilidad objetiva, lo cual vendría a subjetivizar el reconocimiento de la imprudencia. Probablemente estas confusiones tienen que ver con los diferentes

\footnotetext{
${ }^{20}$ KINDHÄUSER, Urs, "El denominado riesgo no permitido", en: EL MISMO, Crítica a la teoría de la imputación objetiva y función del tipo subjetivo. Tres Estudios, Lima: Grijley, 2007, p. 80.

${ }^{21}$ BINDING, La culpabilidad, cit. nota $\mathrm{n}^{\circ}$ 19, p. 145.

${ }^{22}$ Nótese que la dogmática del delito imprudente no pretende imponer estándares que reduzcan todo riesgo de accidente. Porque reducir la probabilidad de resultado típico a cero, o sea, asegurar su no ocurrencia, implicaría la asunción de medidas excesivas que limitarían la ejecución beneficiosa de la actividad. Y como esta conclusión no es sensata, pues toda actividad social útil conlleva un riesgo de resultado lesivo, entonces incluso la actuación cuidadosa implica la asunción de un mínimo de riesgo.

${ }^{23}$ Con la misma preocupación, HART, "Negligence", cit. nota n ${ }^{\circ}$, p. 153 y s.

${ }^{24}$ Véase infra, capítulo 3.4, en donde tal idea lleva a la asunción de una posición individualizadora.

${ }^{25}$ BINDING, La culpabilidad, cit. nota ${ }^{\circ} 19$, p. 145.
} 
REYES, Italo. "Sobre la construcción de la exigencia de cuidado".

significados que pueden darse a los conceptos objetivo y subjetivo, pero lo que nos interesa es lo siguiente: el cuidado exigido a un partícipe queda determinado jurídica y equivalentemente para todos los que cuentan con las mismas capacidades y actúan bajo las mismas circunstancias. En tal sentido, es cierto que enfocar la atención en el específico sujeto que realiza la conducta para determinar la imprudencia implica una individualización, pero siempre una individualización del estándar.

En definitiva, la manera en que determinamos cuándo un sujeto se ha comportado de forma imprudente tiene que realizarse mediante un estándar objetivo que exija de manera equivalente a quienes tengan la misma capacidad y actúen en un mismo contexto ${ }^{26}$. Si las circunstancias en las que el sujeto opera se ven modificadas es evidente que las medidas de precaución también cambian, de modo que comparar diferentes niveles de cuidado conlleva asumir iguales circunstancias de actuación. Nótese, incluso, que el contexto de actuación tiene tal relevancia que modifica las expectativas de cuidado respecto de la misma persona: no se le exige lo mismo a aquel médico que tiene que diagnosticar y tratar una enfermedad en circunstancias "normales" que aquél que debe hacer lo mismo en la vía pública luego de un accidente que sufrió un peatón al ser atropellado por un vehículo. Ello no implica que toleremos descuidos de su parte sino que es el propio estándar el que resulta alterado pues, primero, a cualquier médico en la misma situación tiene que exigírsele lo mismo y, segundo, es comprensible que la situación de urgencia afecte los niveles de cuidado. De tal forma, la asunción de un estándar objetivo permite dar cuenta de forma equivalente de la precaución exigida a un sujeto determinado en un contexto determinado.

\section{La irrenunciable noción de cuidado.}

Existe bastante acuerdo en la doctrina que la primera inclusión sistemática del concepto de deber (o exigencia) de cuidado como elemento medular en la afirmación de imprudencia fue realizada por Karl Engisch en la primera mitad del siglo XX, quien planteó una diferencia entre un deber objetivo (externo) de cuidado y un deber subjetivo (interno) de cuidado. ${ }^{27}$ Lo novedoso de la propuesta de Engisch no era el recurso a la noción de cuidado, pues numerosos autores lo habían utilizado previamente, sino que tal concepto devenía en el punto central de la discusión sobre la imprudencia y, por sobretodo, que su comprensión de deber de cuidado externo por primera vez no quedaba radicada en sede de culpabilidad sino en sede de injusto.

Así, a partir de la segunda mitad del siglo XX en el derecho continental, la discusión dogmática sobre la imprudencia ha asumido como fundamental a la exigencia de cuidado ${ }^{28}$

\footnotetext{
${ }^{26}$ Incluso asumiendo una perspectiva generalizadora, que supone capacidades y conocimientos promedios, la premisa sigue siendo un estándar objetivo. Véase infra, capítulo 4.1.

${ }_{27}$ Tal opinión fue expresada en la célebre Untersuchen über Vorsatz und Fahrlässigkeit im Strafrecht, Berlin, 1930, reimpresión Scientia Verlag, Aalen, 1964. Para mayor detalle sobre la importancia de esta obra, véase PÉREZ DEL VALLE, La imprudencia, cit. nota n 2, pp. 100 y ss.; TORÍO LÓPEZ, Ángel, "El deber objetivo de cuidado en los delitos culposos", Anuario de derecho penal y ciencias penales, tomo XXVII (1974), pp. 26 y ss.

${ }^{28}$ En el mismo sentido, ROSAS, Juan Ignacio, "La delimitación del deber de cuidado en la imputación de responsabilidad penal por imprudencia médica", Doctrina y jurisprudencia penal n ${ }^{\circ} 5$ (2011), p. 1. Asimismo, véase HERNÁNDEZ, Héctor, "Comentario al artículo 2"”, en: COUSO, Javier y HERNÁNDEZ, Héctor
} 
Polít. crim. Vol. 10, № 19 (Julio 2015), Art. 3, pp. 56-91.

[http://www.politicacriminal.cl/Vol_10/n_19/Vol10N19A3.pdf]

y ha librado esfuerzos en desentrañar su contenido o formular elementos adicionales que vendrían a completar el esquema de imputación subjetiva. Dentro de tal corriente, por cierto, se enmarcan los esfuerzos de esta investigación.

De todas maneras, han surgido posiciones discrepantes que rechazan el concepto de cuidado por considerarlo innecesario, centrando el análisis simplemente en la posibilidad del sujeto de conocer el resultado típico ${ }^{29}$. En otras palabras, comprobándose la causalidad del resultado, lo único interesante para determinar la imprudencia es si el sujeto podía haber previsto y evitado su ocurrencia ${ }^{30}$. De tal forma, con algunos matices, lo relevante estaría simplemente en un elemento de previsibilidad o cognoscibilidad, haciendo superfluo el recurso conceptual al cuidado. Puesto que si, para la afirmación de dolo, la representación de las circunstancias fácticas funge como condición necesaria y suficiente -para una teoría cognitiva- o en todo caso como una condición necesaria - para una teoría volitivaentonces, para la afirmación de imprudencia, sólo tendría que reemplazarse esa necesidad de previsión de las circunstancias típicamente relevantes por la posibilidad de preverlas. Esto es, el quid de la imprudencia estaría en una capacidad potencial del sujeto. De tal modo, no existiría un deber de desempeñarse cuidadosamente sino que el contenido de la imprudencia se agotaría en la evitación de acciones cognosciblemente típicas, lo que se podría lograr omitiendo la acción respectiva o adquiriendo los conocimientos necesarios ${ }^{31}$.

\subsection{Delito imprudente como tipo abierto?}

Uno de los argumentos que utiliza la posición contraria al cuidado es que su incorporación implicaría deficiencias sistemáticas y de fundamentación en la comprensión del delito imprudente. Así, que el cuidado sea utilizado como el concepto central para dar por satisfecha la descripción típica del cuasidelito, conllevaría convertir esos tipos en tipos abiertos $^{32}$. El argumento opera enfatizando la escasez de determinación del tipo imprudente puesto que sería el juez quien, en todo caso, tendría que concretar lo que resulta cuidadoso en la situación respectiva. De modo que si el tipo tiene como objetivo básico la selección de sólo algunos comportamientos como jurídico penalmente relevantes, entonces tal

(Eds.), Código penal comentado, Santiago: Abeledo Perrot, 2011, p. 108 para revisar el consenso respectivo en la doctrina nacional.

${ }^{29}$ Véase BURKHARDT, Björn, "Conducta típica y perspectiva ex ante. A la vez, una aportación contra la confusión entre lo subjetivo y lo objetivo", en: WOLTER, Jürgen y FREUND, Georg (Eds.), Sistema integral de Derecho Penal, Barcelona: Marcial Pons, 2004, p. 179. Véase además CORCOY, "El delito imprudente", cit. nota $\mathrm{n}^{\circ} 13$, pp. 45 , con ulteriores referencias.

${ }^{30}$ Véase cita a Rodríguez Devesa en TORÍO, "El deber objetivo", cit. nota n 27, p. 52.

${ }^{31}$ En sentido similar, CURY, Enrique, Derecho Penal, parte general, $7^{\text {a }}$ edición, Santiago: Ediciones Pontificia Universidad Católica, 2007, p. 333 quien renuncia a la caracterización de la imprudencia en base al concepto de cuidado enfatizando, en cambio, la omisión del autor de la medida de dirección final que el hombre medio es capaz. Por su parte, ETCHEBERRY, Alfredo, Derecho Penal, $3^{\text {a }}$ Ed., Santiago: Editorial Jurídica de Chile, 1998, Tomo I, pp. 314 s., si bien reconoce el deber de cuidado, define la imprudencia enfocándose en "la obligación específica de prever los posibles resultados del acto querido, y de conducirse de modo de evitarlos. Culpa vendría siendo (...) "no prever lo previsible, debiendo haberlo previsto". Finalmente, OVALLE, "Imprudencia y cognición", cit. nota $n^{\circ}$ 6, p. 2 señala que "para imputar (calificar y atribuir) como imprudente una cierta conducta a un sujeto, basta que las circunstancias de su dominio sean cognoscibles".

${ }^{32}$ TORÍO, "El deber objetivo", cit. nota nº 27, p. 52. 
REYES, Italo. "Sobre la construcción de la exigencia de cuidado".

delimitación tiene que realizarse con suficiente exactitud por mandato del principio de legalidad. Las leyes penales en blanco definen paradigmáticamente la infracción a ese mandato puesto que su descripción típica es sólo parcial ya que una parte de ella requiere ser complementada posteriormente a través de preceptos dictados por otra autoridad ${ }^{33}$. Lo que sugiere la crítica no es que todo delito imprudente sea una ley penal en blanco, pues no existe otra autoridad que deba dictar una regla para colmar la descripción, sino que el legislador le encargaría al juez la determinación del concepto medular de la imprudencia mediante un mandato excesivo de discrecionalidad que estaría en conflicto con el mandato de determinación ${ }^{34}$.

La defensa del concepto de cuidado ante tal crítica se basa en una diferenciación estricta entre objeto y criterio de imputación ${ }^{35}$. Ya señalábamos que por medio del proceso de imputación es posible relacionar un comportamiento con relevancia delictiva con un determinado sujeto. De tal forma, la imputación presupone un proceso lógico previo de subsunción de una conducta bajo un tipo penal específico con lo cual ésta adquiere interés jurídico penal. La subsunción simplemente pone en evidencia la contradicción entre una norma y la forma de realización de una conducta. Es decir, implica aseverar que ella es antinormativa $^{36}$ y que, por tanto, se configura el ámbito objetivo del injusto. Claro que esa conducta, que adquiere relevancia delictiva al ser subsumida bajo una norma penal, carecerá de conexión con sujeto alguno mientras no sea imputada en atención a sus capacidades. De ahí que el comportamiento antinormativo ocupe la posición de objeto de la imputación, mientras que el reconocimiento de diferentes niveles de capacidad de evitación de ese comportamiento opere como las razones o criterios de esa imputación. Nótese que lo antinormativo del comportamiento, por tanto, no depende de estas reglas de imputación sino que depende únicamente de la descripción típica pertinente. Sólo a través de la subsunción de normas penales se pueden diferenciar aquellas conductas que tienen interés jurídico penal de las que no lo tienen.

Entonces, si, por un lado, el principio de legalidad -concretado como mandato de determinación- exige que la ley describa con suficiente precisión la conducta prohibida o

${ }^{33}$ NOVOA MONREAL, Eduardo, Curso de Derecho Penal Chileno, parte general, Tomo I, $3^{\text {a }}$ Ed., Santiago: Editorial Jurídica de Chile, 2005, p. 117. Véase CURY, Derecho Penal, cit. nota $n^{\circ}$ 31, p. 175 para una diferenciación entre ley penal en blanco propia o impropia, de acuerdo a la jerarquía de la autoridad que debe completar el tipo.

${ }^{34} \mathrm{Al}$ respecto, $\mathrm{CORCOY,} \mathrm{"El} \mathrm{delito} \mathrm{imprudente",} \mathrm{cit.} \mathrm{nota} \mathrm{n}^{\circ} 13$, pp. 80, con ulteriores referencias.

${ }^{35}$ Una mala defensa del concepto de cuidado es la que realiza TORÍO ("El deber objetivo", cit. nota no $27, \mathrm{p}$. 52) en la forma de una evasiva, al señalar que la crítica sólo es pertinente si situamos a la imprudencia en nivel de injusto, pero si lo hacemos en nivel de culpabilidad entonces no existiría el problema señalado. En específico, Torío plantea que la crítica del tipo penal abierto de los delitos imprudentes no puede alcanzar a quienes "estimen que dicho elemento (la infracción del cuidado debido) no pertenece a la tipicidad ni a la antijuridicidad, sino que presuponiendo la acción típica y antijurídica ha de ser atribuido al juicio de culpabilidad, de forma que si el sujeto cumplió con el cuidado generalmente debido, se traza un límite al examen de si, en virtud de sus cualidades excepcionales, pudo prever y evitar personalmente el resultado". En mi opinión, la respuesta de Torío sigue sin ser convincente pues la crítica apunta a la excesiva discrecionalidad del juez en la determinación de lo que resultaba cuidadoso, lo cual se mantiene situando a la imprudencia en el injusto o en la culpabilidad. Quizás Torío tenía en mente una posición finalista que requiere de infracción de normas de cuidado (diferentes de la norma de prohibición) para afirmar imprudencia, pero la crítica no tiene por qué circunscribirse a esta teoría.

${ }^{36}$ MAÑALICH, "Norma e imputación”, cit. nota nº 4, p. 176. 
Polít. crim. Vol. 10, No 19 (Julio 2015), Art. 3, pp. 56-91.

[http://www.politicacriminal.cl/Vol_10/n_19/Vol10N19A3.pdf]

mandada y, por otro, la norma penal sólo juega un papel activo durante el proceso de subsunción al relacionar norma y conducta, entonces la conclusión evidente es que el mandato de determinación sólo puede reclamar pertinencia en el ámbito del injusto objetivo. Allí es donde se analiza si una específica conducta tiene relevancia penal al entenderse como particularización de la descripción abstracta indicada en la norma; y, por tanto, donde el principio de legalidad no tolera una amplitud exacerbada de los términos utilizados por la ley, pues podrían generarse legítimas dudas sobre si una conducta está o no prohibida (o mandada). Sin embargo, cuando nos concentramos en el injusto subjetivo, el proceso lógico ya no observa directamente a la norma penal sino que se enfoca en la relación entre un sujeto y su eventual conducta, de manera que el alegato de escasa determinación de los conceptos queda fuera de lugar.

Por consiguiente, sostener la indeterminación del concepto de cuidado como contrario al mandato de determinación resulta tan poco convincente como sostener la indeterminación del concepto de dolo. Porque nadie estaría dispuesto a plantear que como no existe una definición escriturada del dolo, entonces hay infracción del principio de legalidad. Y esto se basa en que el mandato de determinación apunta a una suficiente descripción de los elementos típicos, lo cual tiene que quedar necesariamente circunscrito al ámbito del tipo objetivo. Allí es donde opera el proceso de subsunción que examina la pertinencia del comportamiento como una instancia del tipo delictivo. Por el contrario, en el proceso de imputación se utilizan numerosos conceptos abiertos que han suscitado discusión en la dogmática, pero respecto de los cuales no cabe una queja por legalidad.

De ahí que alegar indeterminación del concepto de imprudencia como una infracción del principio de legalidad sea simplemente una impropiedad. La única forma en que tal reclamo puede resultar razonable es si se postulase que el cuasidelito atenta en contra una norma diferente a la norma de comportamiento del delito doloso, cual es la postura que sostuviera la teoría final de la acción ${ }^{37}$. En ese caso, podría tener sentido el alegato de indeterminación puesto que esta norma (penal) de cuidado operaría como una norma sometida a las exigencias del principio de legalidad. En tal sentido, los artículos 490 y siguientes se referirían a normas de prohibición independientes a las implicadas en el título VII de Crímenes y simples delitos contra las personas. Así, el art. 391 sólo vendría en consideración respecto de un delito a título de dolo. Bajo tal comprensión, parece evidente que la noción de cuidado sería un elemento de la descripción típica-como concreción de las nociones de imprudencia o negligencia- y que estaría sometido al mandato de determinación.

El finalismo, en este sentido, trae consigo la antigua discusión relativa al reconocimiento de crimen culpae o crimina culposa en el ordenamiento jurídico. Porque, de acuerdo con sus premisas, la imprudencia conllevaría que todo delito culposo atentara en contra de un mismo bien jurídico de conducción cuidadosa, independiente del resultado provocado por

\footnotetext{
${ }^{37}$ TORÍO, "El deber objetivo", cit. nota n ${ }^{\circ} 27$, p. 44. En un sentido similar, véase ETCHEBERRY, Derecho Penal, cit. nota $\mathrm{n}^{\circ}$ 31, p. 315 quien aplicando las premisas de la teoría finalista a la imprudencia sostiene que "existe un deber de prudencia general y autónomo: ser prudentes para evitar cualquier daño a otro". Para un análisis detallado, véase CORCOY, "El delito imprudente", cit. nota n 13, pp. 89 y ss.
} 
REYES, Italo. "Sobre la construcción de la exigencia de cuidado".

la conducta $^{38}$. Ello se opone a la extendida intuición dogmática de entender al dolo y la imprudencia como elementos subjetivos sistemáticamente equivalentes, al reconocer específicamente normas que prohibirían conductas a título de dolo y normas que prohibirían conductas a título de imprudencia. De tal forma, bajo un sistema de crimen culpae, como el finalista, no es, en estricto rigor, adecuado hablar de un delito de homicidio imprudente sino, más bien, de un delito de imprudencia con resultado de muerte ${ }^{39}$.

Ahora bien, entender que los artículos 490 y siguientes aluden a normas de prohibición independientes desconoce la distinción entre normas de sanción y normas de prohibición que hiciera célebre Karl Binding a finales del siglo XIX. Si las normas de prohibición (y de mandato) se entienden como el estándar que se ve quebrantado con el comportamiento punible, entonces no se corresponden con las normas escrituradas en la ley, las cuales, por el contrario, se ven realizadas cada vez que se comete un delito ${ }^{40}$. De tal modo, las normas de prohibición no están formuladas en la ley sino que sólo se dejan formular a partir de ella. En tal sentido, tanto el art. 391 como el art. 490 sólo cuentan como normas de sanción que especifican las condiciones y consecuencias que el legislador ha decidido respecto del quebrantamiento de la prohibición del homicidio. El art. 490 es necesario porque nuestro código, en atención al art. $10 \mathrm{n}^{\circ} 13$, asume un sistema de numerus clausus para la sanción del delito imprudente de modo que se requiere que la ley explicite qué delitos serán sancionados no sólo a título de dolo sino también a título de imprudencia.

Así, el delito imprudente no puede ser entendido como un delito común de imprudencia con diversos resultados (crimen culpae: crimen de culpa) sino como delitos independientes que infringen normas de prohibición también diferentes según el comportamiento ejecutado (crimina culposa: crímenes culposos), observando como común denominador a la ausencia de dolo y una infracción de una exigencia de cuidado como razón para atribuir ese comportamiento al sujeto. De tal forma, un cuasidelito de homicidio infringe la misma norma de comportamiento que un homicidio doloso, tan sólo diferenciándose en el esquema de imputación en referencia ${ }^{41-42}$.

\footnotetext{
38 TORÍO LÓPEZ, Ángel, "Sobre los límites de la ejecución por imprudencia”, Anuario de derecho penal y ciencias penales, tomo XXV (1972), p. 67. Esta discusión era especialmente compleja bajo un ordenamiento como el español con el código ya derogado que incorporaba un art. 565 que permitía la punibilidad general del delito imprudente en la forma de un sistema de numerus apertus. Ello llevaba a que el finalismo afirmara con facilidad que tal norma hacía referencia a un delito sui generis comprometido con un sistema de crimen culpae. Sin embargo, igualmente la doctrina causalista tradicional española de la época argumentaba a favor de delitos imprudentes independientes teniendo el art. 565 más bien una función interpretativa.

${ }^{39}$ Véase TORÍO, "Sobre los límites", cit. nota no 38, p. 70. En un sentido similar, ETCHEBERRY, Derecho Penal, cit. nota $\mathrm{n}^{\mathrm{o}}$ 31, p. 315 al sostener que todo delito imprudente infringe un mismo deber de prudencia general.

${ }^{40}$ MAÑALICH, "Norma e imputación”, cit. nota n 4, p. 171. En el mismo sentido, TORÍO, "Sobre los límites", cit. nota n 38 , p. 67 , nota 31 .

${ }^{41}$ En contra, CORCOY, "El delito imprudente", cit. nota ${ }^{\circ} 13$, pp. 92 y ss.

${ }^{42}$ Ello implica sostener que el tipo objetivo de delitos dolosos e imprudentes análogos es necesariamente el mismo pues la diferencia entre ellos sólo puede observarse en el ámbito subjetivo del injusto. Empero, no seguiremos analizando este argumento pues su desarrollo nos alejaría del objeto de esta investigación. Claramente en contra, CORCOY, "El delito imprudente", cit. nota n 13, pp. 43 y ss., 245 y ss.
} 
Polít. crim. Vol. 10, № 19 (Julio 2015), Art. 3, pp. 56-91.

[http://www.politicacriminal.cl/Vol_10/n_19/Vol10N19A3.pdf]

Lo relevante, por tanto, no es simplemente el planteamiento como indeterminado de un concepto para observar una infracción al principio de legalidad, pues numerosos conceptos jurídicos carecen de una definición estricta y pueden ser dotados de contenidos diversos dependiendo de la posición doctrinaria defendida. De ahí que la única indeterminación que puede ser relevante para el principio de legalidad es la indeterminación de la descripción típica: si no está clara la conducta prohibida o mandada entonces hay infracción del mandato de determinación. Y como un concepto de imprudencia bien entendida sólo se discute en la imputación de la conducta como infracción culpable de deber y nunca en la discusión sobre la subsunción del comportamiento en la norma, entonces el alegato de ilegitimidad del cuidado como fundamento de la imprudencia queda completamente fuera de lugar ${ }^{43}$.

\subsection{La previsibilidad y el cuidado.}

\subsubsection{Desentrañando la previsibilidad.}

No obstante, aún no hemos respondido la crítica al concepto de cuidado, a saber: resulta superfluo porque un requisito de previsibilidad o cognoscibilidad es suficiente para entender cuando existe un comportamiento imprudente. Asumiendo esta postura, lo relevante es que "el autor del hecho injusto, partiendo de sus conocimientos parciales, estaba en condiciones de llegar a un conocimiento de todo el acontecer, esto es, en condiciones de conocer el hecho y su injusto" 44 , lo cual fundamentaría la imprudencia sin necesidad de recurrir a la noción de cuidado.

En apariencia, la crítica tiene sentido: ¿para qué necesitamos incorporar conceptos adicionales (y complejos) en la determinación de la imprudencia si la mera referencia a la posibilidad de conocer basta? Y la respuesta pasa por desentrañar qué implica el requisito de previsibilidad y, por tanto, "qué está detrás de él". Trabajemos con un ejemplo: el médico A realiza una determinada intervención quirúrgica sin siquiera notar que la técnica utilizada era contraindicada para el paciente $P$, lo que desencadena su muerte ${ }^{45}$. En este caso de imprudencia inconsciente, los defensores de la cognoscibilidad sostendrían que A

\footnotetext{
${ }^{43}$ En sentido similar, TORÍO, "Sobre los límites", cit. nota $n^{\circ} 38$, p. 69, quien entiende que el reclamo por legalidad es inconducente respecto de la imprudencia, pero que debido a su adhesión al causalismo (probablemente por la época en que escribe) entiende a los elementos de dolo y culpa en sede de culpabilidad. Sin embargo, la intuición es enteramente correcta: "la doctrina de los crimina culposa supone que el tipo es en ciertos delitos igual para delito doloso y culposo, con lo que el argumento de que el artículo 565 [norma similar a nuestro art. 490] deja sin precisar la materia prohibida, deviene inexacto, pues esta disposición no contiene la materia prohibida, es decir, el tipo, sino una forma de culpabilidad".

${ }^{44}$ BURKHARDT, "Conducta típica", cit. nota n ${ }^{\circ} 29$, p. 180, donde cita a Schmidhäuser. En el mismo sentido, OVALLE, "Imprudencia y cognición", cit. nota $\mathrm{n}^{\circ}$ 6, p. 2. Téngase en cuenta que la afirmación de que el autor deba conocer el injusto de su acción introduce una confusión entre los dos niveles de la imputación, puesto que si se sostiene que la noción de imprudencia tiene relevancia en el primer nivel, entonces la referencia al conocimiento de lo antijurídico del comportamiento debiera quedar vedada pues tal consideración pertenece al segundo nivel de imputación, cual es, el correspondiente al análisis de culpabilidad. A pesar de esta complicación, en lo que sigue se enfocarán esfuerzos en lo igualmente deficiente que resulta una postura que acude simplemente a la cognoscibilidad rechazando la noción de cuidado.

${ }^{45}$ Para una revisión detallada de las exigencias derivadas de la lex artis médica, véase ROSAS, "La delimitación", cit. nota n ${ }^{\circ} 28$, pp. 5 y ss.
} 
REYES, Italo. "Sobre la construcción de la exigencia de cuidado".

es responsable de un cuasidelito de homicidio porque para A era cognoscible, dado sus conocimientos médicos, que aplicaba una técnica incorrecta en la realización de la operación, lo cual desencadenaría la muerte del paciente. Es decir, A tenía la capacidad para prever que la técnica era inadecuada y que su ejecución conllevaría la muerte del paciente.

Ahora bien, lo interesante está en desentrañar la noción de cognoscibilidad o previsibilidad. Y ambos conceptos se estructuran en la forma de una oración condicional irreal puesto que se refiere a lo que el sujeto podría haber conocido a pesar de que ello no ocurrió, en atención a una determinada razón ${ }^{46}$. En el ejemplo queda claro lo condicional de la afirmación porque se apunta a lo que el cirujano hubiera sabido, pero que en realidad no supo: como médico, A hubiera sabido que la técnica era incorrecta y provocaría la muerte del paciente, pero al momento de la intervención no lo supo, debido a una determinada razón. Lo que resulta interesante es que toda oración condicional irreal se compone de dos partes: una oración secundaria hipotética y una oración principal que opera como consecuencia de esa suposición. La oración secundaria opera como una hipótesis objetiva que explica el carácter condicional irreal de la oración principal ${ }^{47}$. Por ejemplo: la oración condicional irreal "Si mi padre no hubiese muerto durante el embarazo de mi madre, yo lo habría conocido". La última parte corresponde a la oración principal e implica, primeramente, que en realidad yo no conocí a mi padre, pero además requiere una suposición que explique su irrealidad. Sin la oración secundaria hipotética, la mera afirmación "yo habría conocido a mi padre" resulta incompleta. El punto está en que los detractores del concepto de cuidado pasan por alto esta situación de índole semántica. No interesa solamente que el sujeto podría haber conocido sino también la razón por la cual no conoció.

La pregunta, entonces, es cuál es la hipótesis objetiva que entrega la posibilidad de haber conocido (o previsto) el injusto penal que desencadenó la conducta del sujeto, y para ello se pueden sostener dos alternativas. La primera atiende a la motivación (general) conforme a derecho del supuesto autor: el sujeto habría conocido que su conducta era antijurídica si hubiese estado suficientemente motivado en evitar una situación de incapacidad, esto es, si se hubiese comportado como un ciudadano fiel al derecho. En nuestro ejemplo: A habría sabido que la técnica era incorrecta y causaría la muerte del paciente si hubiese actuado como ciudadano fiel a derecho. El problema es que la argumentación se vuelve circular porque presupone lo que precisamente se pretende afirmar. Si el ámbito del injusto subjetivo pretende determinar si el autor opuso su voluntad individual a la voluntad general del ordenamiento jurídico por medio de la verificación de la capacidad de evitación intencional, entonces tomamos como presupuesto que el sujeto reconoce la validez de la norma como razón para su acción ${ }^{48}$ o, que es lo mismo, suponemos que se trata de un ciudadano fiel a derecho. Al comprobar que el sujeto era capaz de evitar la conducta típica estamos afirmando que, en realidad, éste no reconoció a la norma penal como premisa de su comportamiento, de manera que se justifica un reproche en su contra. De tal modo, la motivación (general) conforme a derecho no puede ser la manera de explicar la oración

\footnotetext{
${ }^{46}$ BURKHARDT, "Conducta típica”, cit. nota no 29, p. 181.

${ }^{47}$ BURKHARDT, "Conducta típica", cit. nota n' 29, p. 182.

${ }^{48}$ MAÑALICH, Juan Pablo, Norma, causalidad y acción, Madrid: Marcial Pons, 2014, p. 24.
} 
Polít. crim. Vol. 10, No 19 (Julio 2015), Art. 3, pp. 56-91.

[http://www.politicacriminal.cl/Vol_10/n_19/Vol10N19A3.pdf]

condicional irreal ya que su referencia sólo puede explicitar las condiciones contrafácticas de la actividad de imputación.

Una segunda alternativa postularía que la hipótesis objetiva está comprometida con una exigencia de cuidado que ha sido infringida por el autor en la ejecución de la conducta y que justificaría la imputación a título de imprudencia. De acuerdo a las circunstancias de actuación, la exigencia de cuidado se concreta en algún comportamiento específico que hubiese brindado la capacidad del sujeto de evitar el resultado típico. En nuestro ejemplo, la afirmación completa podría ser la siguiente: "A hubiese conocido que la técnica utilizada era incorrecta y provocaría la muerte del paciente si hubiese examinado su expediente médico, cuestión a la que estaba obligado y en condición de realizar". Es decir, de acuerdo a las circunstancias ficticias del caso, A no conoció el riesgo de muerte del paciente debido a que omitió revisar su expediente ${ }^{49}$. En otras palabras, la valoración errónea de la situación -que permite afirmar lo cognoscible del injusto- se debe a no haber empleado el cuidado necesario y posible ${ }^{50}$. En tal sentido, en el ejemplo, la exigencia de cuidado se concreta en un mandato de adquisición de conocimientos mediante la revisión de fichas clínicas.

Por supuesto, la medida de precaución específica exigida al autor es estrictamente dependiente de las circunstancias fácticas que atribuyamos al caso, de manera que ésta puede concretarse en una acción (por ejemplo, el estudio de la ficha médica) o en una omisión (por ejemplo, simplemente no realizar la intervención quirúrgica en condiciones físicas de agotamiento). Ello implica que la exigencia de cuidado no se reduce simplemente en un mandato de adquisición de conocimientos cuya ausencia provoca una valoración errónea del contexto de actuación ${ }^{51}$ sino que, por el contrario, tal exigencia se especifica en mandatos de hacer o en prohibiciones de omitir determinados comportamientos en pos del aseguramiento de la capacidad futura de seguimiento de la norma.

Asimismo, debe tenerse presente que la conducta exigida en atención a cuidado es conceptualmente independiente a la conducta exigida en atención a la norma de comportamiento. Es perfectamente posible que la imputación de una norma de prohibición -que manda que tenga que no hacerse algo, esto es, que algo no se haga $-{ }^{52}$ se actualice en una exigencia de cuidado que obligue hacer algo. Esto es porque la exigencia de cuidado no se relaciona causalmente con la conducta cuidadosa sino sólo motivacionalmente: cumplir con la medida de precaución habilita al autor para evitar la infracción de la norma de comportamiento. En otras palabras, en el ámbito de la imprudencia, no hay confrontación entre un comportamiento y el contenido de una norma, como sí existe en la subsunción del

\footnotetext{
${ }^{49}$ De acuerdo con ROSAS, "La delimitación”, cit. nota ${ }^{\circ} 28$, p. 5, en la etapa de ejecución de la actividad médica, el facultativo debe conocer la eficacia de los medios empleados y la reacción del organismo del paciente, lo cual no se verificaría en nuestro caso.

${ }^{50}$ BURKHARDT, "Conducta típica", cit. nota n' 29, p. 182

${ }^{51}$ En cierto sentido, en contra, BURKHARDT, "Conducta típica", cit. nota $\mathrm{n}^{\circ} 29, \mathrm{p} .174$ pues entiende que el cuidado interno se refiere siempre a un mandato de adquisición de conocimientos. Dado que la noción de cuidado externo no es propia del delito imprudente, entonces la falta de cuidado estaría íntimamente ligada a una valoración errónea de los hechos por una carencia de conocimientos.

52 Para una revisión de los elementos de una norma, especialmente el carácter y el contenido, véase VON WRIGHT, Georg Henrik, Norma y acción, Madrid: Editorial Tecnos, 1970, pp. 87 y ss.
} 
REYES, Italo. "Sobre la construcción de la exigencia de cuidado".

tipo objetivo; sino que una determinada acción u omisión expresa un aseguramiento de capacidades futuras en la forma de un deber de cuidado.

En definitiva, lo relevante es que los conocimientos actuales y potenciales del sujeto no definen si una conducta es o no imprudente, pues sólo constituyen un elemento integrante de la exigencia de cuidado. En tal sentido, Björn Burkhardt está en lo correcto al entender que la falta de cuidado está incluida como componente normativo en el concepto de $\operatorname{cognoscibilidad}^{53}$, en el sentido de que la capacidad potencial de conocimiento de las circunstancias relevantes del injusto típico está mediada por un concepto normativo de cuidado que explica las razones por las cuales el sujeto tenía tal capacidad. Porque fundar la imprudencia en una consideración de previsibilidad que excluya elementos normativos, en un sentido radicalmente sicológico, aludiría a una posibilidad o capacidad de prever vacía porque no podría convertirse en una exigencia al sujeto de realizar determinada conducta ${ }^{54}$. Que el sujeto simplemente tenga la capacidad para hacer algo es irrelevante sin un adicional normativo que lo obligue, en atención a esa capacidad, a ejecutar u omitir una conducta. Considerado este elemento normativo en la misma noción de previsibilidad, entonces el recurso al concepto de cuidado es ineludible: detrás de la previsibilidad siempre está la exigencia de comportarse cuidadosamente.

\subsubsection{La previsibilidad como elemento adicional.}

a) Aplicando las ideas planteadas al contexto regulativo nacional, si bien nuestra doctrina y jurisprudencia nunca han desconocido un requisito de infracción de deber de cuidado para el reconocimiento del cuasidelito, es opinión mayoritaria que además debe exigirse un elemento de previsibilidad ${ }^{55}$. De acuerdo con la reconstrucción aquí sostenida, tal requisito adicional de previsibilidad no debe ser entendido como una condición incorrecta sino que enteramente superflua: cada vez que se concluya que el autor ha quebrantado la exigencia de cuidado a la que estaba obligado según las circunstancias de actuación, también se concluye al mismo tiempo que pudo prever las consecuencias típicas de su conducta.

Porque la legítima preocupación de la doctrina y la jurisprudencia chilena al sostener un requisito adicional de previsibilidad del resultado está en que nadie puede ser responsable por un acontecimiento fortuito, pues, en términos de imputación, un acontecimiento fortuito es aquel respecto del cual el sujeto carece absolutamente de capacidad para su evitación. Lo relevante para la imputación está, entonces, en que siempre tiene que ser necesario observar alguna posibilidad de evitación del resultado lesivo, lo cual puede verificarse en forma directa por medio del dolo o en una forma indirecta por medio de la imprudencia. Si no hay

\footnotetext{
${ }^{53}$ BURKHARDT, "Conducta típica”, cit. nota n ${ }^{\circ}$ 29, p. 180. Lo fundamental de la tesis de Burkhardt no está en la subordinación conceptual del cuidado bajo la cognoscibilidad, sino más bien en su íntima relación. Es decir, no se puede hablar de uno sin la otra. De tal manera, cuál elemento se supedita a cuál no resulta determinante pues, en último término, va a depender de la primacía que se le dé a cada uno. Lo relevante está siempre en la conexión conceptual entre ambos.

54 Téngase presente que ésta no es la propuesta de todas las posiciones contrarias al cuidado, pues muchas veces se reconoce un deber de previsibilidad en la forma de un deber de cuidado interno. Véase, por ejemplo, HERNÁNDEZ, "Comentario", cit. nota n² 28, p. 110.

55 En la doctrina, véase por todos NOVOA, Curso de derecho penal, cit. nota $\mathrm{n}^{\circ}$ 33, p. 504; en la jurisprudencia véase SCS 15.09.2008, Rol n 7070-07, Contra Santos Sanelli, Legal Publishing, Cita Online CL/JUR/5218/2008.
} 
Polít. crim. Vol. 10, № 19 (Julio 2015), Art. 3, pp. 56-91.

[http://www.politicacriminal.cl/Vol_10/n_19/Vol10N19A3.pdf]

posibilidad de evitación, entonces por mandato del principio ultra posse nemo obligatur, no puede haber responsabilidad penal. En ese sentido, la preocupación de la doctrina tradicional está totalmente justificada.

Sin embargo, el requisito de previsibilidad no debe ser entendido como un criterio puramente psicológico, en el sentido que el resultado pudiera "pasar por la mente" del autor à la Turner, ya que lo interesante radica en la imperiosa comprobación de la capacidad de evitación. En tal sentido, no es necesario postular una exigencia adicional de previsibilidad pues una adecuada configuración de la exigencia de cuidado ya cumple con el propósito de examinar si hubiese podido evitarse la situación de inevitabilidad de producción de resultado lesivo. Si se concluye la infracción de tal deber de cuidado entonces, al mismo tiempo, se está afirmando la posibilidad de que, con el actuar cuidadoso que se le exigía, el sujeto podría haber quedado en situación de evitar el accidente. En otras palabras, si la exigencia de cuidado es entendida como la razón por la cual se imputa extraordinariamente una conducta antinormativa a un sujeto, en atención a que contaba con la capacidad de asegurar su capacidad de evitación futura y no se comportó de acuerdo a esa finalidad, entonces nunca se concluirá una infracción de la exigencia de cuidado en donde el resultado resulte imprevisible al sujeto, pues ello implicaría negarle su estatus como criterio de imputación ${ }^{56}$.

b) En este ámbito, puede ser interesante revisar brevemente el planteamiento de la doctrina mayoritaria al identificar un doble deber de cuidado: un cuidado interno referido al deber de observación de condiciones y consecuencias peligrosas del comportamiento realizado, lo cual se entendería como un deber de previsibilidad; y un cuidado externo que exigiría adecuar la conducta al peligro observado con el objeto de evitar un resultado típico ${ }^{57}$. Este cuidado externo se concretaría en tres mandatos diferentes según el contexto: ya sea un deber de omisión de acciones peligrosas, un deber de adquisición de conocimientos o un deber de actuar prudente ${ }^{58}$.

El problema está en que diferenciar conceptualmente la previsibilidad y las medidas de precaución que deben adoptarse según la situación parece indicar que son dos categorías diferenciadas cuando están íntimamente vinculadas. Y ni siquiera se trata de que la previsibilidad sea el presupuesto del deber de cuidado externo ${ }^{59}$, sino que más bien son dos caras de la misma moneda. Si la exigencia de cuidado analiza la capacidad de

\footnotetext{
${ }^{56}$ Aquí se observa una aparente contradicción entre lo sostenido en esta investigación y la conclusión de Burkhardt (explicada en párrafos anteriores). Pues éste afirmaría que el concepto de cuidado está conceptualmente comprendido en la cognoscibilidad, y acá se sostendría lo contrario, esto es, que el cuidado implica la cognoscibilidad. La contradicción es aparente porque, en mi opinión, la tesis de Burkhardt no se reduce a determinar cuál elemento se subordina al otro sino en evidenciar su íntima conexión. En ese sentido, la primacía va a depender de cuál de ellos sea entendido como central por la teoría respectiva, lugar que aquí ocupa la exigencia de cuidado. Lo importante, de nuevo, es que tal asunción no puede implicar que la cognoscibibilidad carezca de relevancia, pues conceptualmente queda supuesta en el cuidado.

${ }^{57}$ ROSAS, "La delimitación", cit. nota n 28, p. 2. En el mismo sentido, véase HERNÁNDEZ, "Comentario", cit. nota ${ }^{\circ} 28$, pp. 110 y ss.

${ }^{58}$ ROSAS, "La delimitación”, cit. nota n 28, p. 2; CORCOY, "El delito imprudente", cit. nota n 13, pp. 153 y ss.

${ }_{59}$ Como indica ROSAS, “La delimitación”, cit. nota ${ }^{\circ} 28$, p. 2.
} 
REYES, Italo. "Sobre la construcción de la exigencia de cuidado".

aseguramiento de capacidades futuras para evitar el resultado típico, entonces no es posible diferenciar, por un lado, la previsibilidad y, por otro, la conducta concreta que cumple tal exigencia, pues la determinación de la medida de precaución específica que debía ejecutar el agente no puede sino incorporar la observación de los peligros asociados a su comportamiento. Por supuesto, la distinción puede tener una finalidad didáctica, pero sólo para evidenciar que hablar de conducta cuidadosa adecuada al contexto supone hablar también de la previsibilidad del resultado típico en ese contexto; y que, viceversa, hablar de un deber de previsibilidad en el ámbito de la imprudencia supone hablar de la conducta preventiva de los riesgos observados ${ }^{60}$.

Y, por lo demás, las tres concreciones tradicionales del deber de cuidado externo resultan bastante arbitrarias. Nadie estaría en desacuerdo al afirmar que el mandato de actuar prudente ya engloba los otros mandatos de omisión de acciones peligrosas y de adquisición de conocimientos, porque según el contexto ésas serían formas de actuar prudente. Pero, como se hace suficientemente evidente en el contexto médico, existen numerosos otros deberes que perfectamente podrían ser entendidos como concreciones del deber de cuidado externo, por ejemplo, el mandato de informar el tratamiento al paciente o de supervigilar a otros miembros del equipo ${ }^{61}$. De tal forma, la tripartición tradicional del cuidado externo simplemente expone aquellas exigencias concretas de mayor ocurrencia práctica, pero sin razones sustanciales que justifiquen la distinción, lo cual, por supuesto, le quita cualquier rendimiento teórico. Empero, ello no quiere decir, de nuevo, que tal clasificación carezca de importancia didáctica para explicar las concreciones más importantes de la exigencia de cuidado.

Lo relevante es que, en definitiva, tanto la distinción entre cuidado interno y externo como la tripartición del cuidado externo no vienen a explicar qué significa que alguien se comporte imprudentemente sino que simplemente enfatizan ciertos elementos que facilitan la explicación del contenido de la imprudencia. Al determinar la conducta que hubiese asegurado la capacidad de evitación futura, el recurso a la exigencia de cuidado implica ya la posibilidad de prever ese resultado, no como elemento adicional sino como parte misma del significado de la locución exigencia de cuidado en tal contexto.

\section{El contenido de la exigencia de cuidado.}

\subsection{La posición generalizadora.}

Respecto a la construcción de la imprudencia, ya afirmamos dos puntos: que debe hacerse bajo un estándar objetivo y que el concepto de cuidado es irrenunciable. No obstante, aún no nos hemos referido a cómo debe construirse tal estándar de cuidado. Y aquí es donde se defenderá una imputación enfocada en el sujeto concreto y, por tanto, considerando sus conocimientos y habilidades especiales para determinar la conducta cuidadosa exigida. Esta postura puede denominarse como individualizadora, en oposición a una generalizadora, la

\footnotetext{
${ }^{60}$ Claramente en contra, CORCOY, "El delito imprudente", cit. nota ${ }^{\circ} 13$, pp. 226 y ss., quien diferencia con rigidez un deber objetivo de cuidado que se analiza en el tipo objetivo y un deber subjetivo de cuidado que se examina en el tipo subjetivo. Sólo en este último se revisan los conceptos de cognoscibilidad, previsibilidad y evitabilidad.

${ }^{61}$ ROSAS, “La delimitación”, cit. nota n² 28 , pp. 5 y ss.
} 
Polít. crim. Vol. 10, No 19 (Julio 2015), Art. 3, pp. 56-91.

[http://www.politicacriminal.cl/Vol_10/n_19/Vol10N19A3.pdf]

cual determina la infracción del deber de cuidado en atención a un hombre medio abstracto con conocimientos y capacidades promedios ${ }^{62}$.

En tal sentido, para comprender la posición generalizadora, puede resultar recomendable volver a Hart. Contradiciendo la posición dominante marcadamente sicológica, Hart sostiene que la razón por la cual se imputa un cuasidelito está en la infracción de un estándar de conducta que le era exigible al sujeto. Sin embargo, considera que es erróneo caracterizar a ese estándar como un estándar puramente objetivo (o nada más que objetivo), pues ello podría implicar la exclusión de todo atisbo subjetivo en la determinación de la responsabilidad penal, lo que resulta contrario al principio de culpabilidad ${ }^{63}$. Para evitar tal conclusión, Hart diferencia dos preguntas estructurales: en primer lugar, si el sujeto falló en tomar las precauciones que cualquier hombre razonable (any reasonable man) con capacidades normales hubiere tomado; y en segundo lugar, si el sujeto específicamente considerado y dado sus capacidades mentales y físicas habría tomado aquellas precauciones. Sin prejuzgar sobre la postura a la que hubiese adscrito Hart en la discusión continental actual, un modelo generalizador también argumenta desde esas dos preguntas ${ }^{64}$.

La preocupación de Hart es que al establecer un estándar fijo de cuidado algunas personas con capacidades inferiores podrían -justificadamente- reclamar que no les era posible evitar la infracción del estándar, pues éste quedaba por encima de sus capacidades. Si aún en ese caso se justifica responsabilidad penal, entonces estaríamos inmersos en un sistema de responsabilidad objetiva. De tal manera, distinguir las dos preguntas permite que los casos excepcionales de sujetos bajo el estándar sean resueltos al alero de la segunda pregunta, sin necesidad de alterar la construcción del estándar (invariable) de cuidado de la primera $^{65}$. De ahí que tal estándar permanezca igual para cada caso y para cada sujeto: el cuidado que hubiese ejercido cualquier hombre razonable con capacidades promedio.

El argumento de Hart puede reinterpretarse en la forma de una postura generalizadora como sigue: por una parte, el estándar de cuidado está ubicado sistemáticamente en el ámbito del injusto; y por otra, únicamente integra los conocimientos y capacidades promedio de un

\footnotetext{
${ }^{62}$ En el mismo sentido, ROSAS, "La delimitación", cit. nota n 28, pp. 2 y ss.

${ }^{63}$ HART ("Negligence", cit. nota $n^{\circ} 9$, p. 152) plantea la odiosidad de la responsabilidad objetiva no sólo porque implica sancionar a quienes al momento de actuar no habían previsto o deseado (mentalmente) la acción sino también porque la responsabilidad penal supone que los autores tienen las capacidades normales para hacer lo que la ley requiere, de modo que si no tienen esas capacidades no pueden ser responsables (por ejemplo, menores de edad o dementes). La responsabilidad objetiva impediría considerar ese tipo de casos.

${ }^{64}$ Para caracterizar adecuadamente el argumento de Hart tiene que diferenciarse la pregunta sistemática y la sustancial. La primera alude a la posición de la imprudencia en la teoría del delito y la segunda a la construcción de la exigencia de cuidado. Como Hart se enmarca en el common law no distingue con rigor las categorías del injusto y de la culpabilidad. Para él, la imprudencia se ubicaría en el contexto del mens rea y, en específico, a lo que se denomina prima facie culpability (Véase MOORE, Michael, "Prima facie culpability", Boston University Law Review vol. 76 (1996), passim). Sólo después de considerar la diferencia estructural, vale la pena preguntarse por la posición de Hart en la construcción del estándar. Y allí resulta dudoso su adscripción a la postura generalizadora o individualizadora, pues ambas preguntas podrían ubicarse tan sólo en categoría de injusto o tanto en el injusto como la culpabilidad. En lo que importa aquí, no resolveremos la pregunta, puesto que simplemente nos interesa el recurso a las dos preguntas, cuestión que también es tematizada por la posición generalizadora.
}

${ }^{65}$ HART, "Negligence", cit. nota no 9, p. 155. 
REYES, Italo. "Sobre la construcción de la exigencia de cuidado".

hombre razonable. Es decir, para afirmar que un determinado comportamiento es antijurídico bastaría que la acción sea considerada imprudente desde el punto de vista de un observador abstracto razonable. Luego, las circunstancias personales del autor sólo serían revisadas en el ámbito de la culpabilidad, en donde se exculpará a aquellos que hayan sido incapaces de cumplir con el estándar objetivo. De tal forma, la primera pregunta estaría referida al injusto y la segunda pregunta a la culpabilidad ${ }^{66}$.

En tal sentido, la posición generalizadora plantea que la acción es contraria a deber si "un observador -hombre medio cuidadoso y atento partícipe en el tráfico social- hubiera podido reconocer la acción como peligrosa para el bien jurídico" ${ }^{\text {67 }}$. Lo que el sujeto concretamente considerado podía (o no podía hacer) es irrelevante en el ámbito del injusto, debiendo considerarse solamente en la culpabilidad.

La importancia que una posición generalizadora otorga a los conocimientos y habilidades promedios - que se analizan en el injusto- en contraste a los conocimientos y habilidades concretos del autor -que se analizan en la culpabilidad- traen consigo tres posibles relaciones. La primera es la más simple: los conocimientos y habilidades del sujeto se corresponden idénticamente con el promedio, de modo que no hay dificultad alguna asociada. La segunda posibilidad es que los conocimientos y habilidades del sujeto sean inferiores al promedio, configurándose la antijuridicidad del comportamiento, pero exculpándose en sede de culpabilidad en atención a la diferenciación estructural de dos preguntas que asume como premisa el modelo. Estos casos son conocidos como de exceso de punibilidad. La última posibilidad es que los conocimientos y habilidades del sujeto sean superiores al promedio, de modo que tales capacidades especiales no serán tomadas en cuenta en el estándar de cuidado. Así, por ejemplo, si el sujeto a imputar es un nadador campeón olímpico, el estándar tendría que construirse sólo de acuerdo a las capacidades de natación promedio, sin ser posible exigirle el desempeño de toda su habilidad. Estos casos son conocidos como lagunas de punibilidad. Nótese que, a diferencia del segundo caso que se resuelve -en la práctica- en sede de culpabilidad ${ }^{68}$, los conocimientos y capacidades especiales superiores nunca son examinados para determinar a lo que el sujeto estaba obligado, pues de no existir injusto subjetivo entonces el análisis de culpabilidad resulta innecesario.

En otras palabras, para imputar la infracción de exigencias de cuidado es necesario que el sujeto haya contado con la posibilidad de examinar el peligro de su acción, para lo cual debe contar con ciertas capacidades y conocimientos. La posición generalizadora cree que es suficiente comparar la acción realizada con la que hubiese realizado un hombre abstracto

\footnotetext{
${ }^{66}$ Para revisar los argumentos de la doctrina nacional al respecto, véase HERNÁNDEZ, "Comentario", cit. nota $\mathrm{n}^{\circ} 28$, pp. 113 y ss., con ulteriores referencias. Allí destaca la discrepancia que existe entre autores "clásicos" pues si bien una gran parte considera los conocimientos especiales para la determinación de la falta de cuidado (Etcheberry, Garrido, Bustos, Labatut), también existe una parte importante que entiende que las capacidades superiores deben ser analizadas en sede de culpabilidad (Novoa, Cury, Náquira, Politoff).

67 ZUGALDÍA, José Miguel, "La infracción del deber individual de cuidado en el sistema del delito culposo", Anuario de derecho penal y ciencias penales, tomo XXXVII, fascículo II (1984), p. 328.

${ }^{68}$ Solamente se resuelve "en la práctica" pues igualmente se afirma que la conducta es antijurídica, a pesar de que el autor se ve posteriormente exculpado, lo cual es crucial para determinar la legitimidad de eventuales causas de justificación en contra de la conducta imprudente injusta.
} 
Polít. crim. Vol. 10, No 19 (Julio 2015), Art. 3, pp. 56-91.

[http://www.politicacriminal.cl/Vol_10/n_19/Vol10N19A3.pdf]

en la situación del autor con capacidades y conocimientos promedios. De esta forma, el ordenamiento está exigiendo actuar de acuerdo a lo que puede y lo que sabe un sujeto promedio en la misma situación, pues de esa manera -argumentan sus partidarios- se exige el mismo nivel de cuidado a todo integrante de la sociedad. Al circunscribir el análisis a un estándar abstracto promedio, aquellos que pueden y saben más quedan obligados en la misma medida que aquellos que pueden y saben en promedio ${ }^{69}$.

Eso sí, esta posición -por lo demás, tradicionalmente mayoritaria- resulta contradictoria con un sistema causalista del delito que diferencia entre un injusto puramente objetivo y la culpabilidad puramente subjetiva. Si la imprudencia sólo era examinada como elemento complementario del dolo en el ámbito de la culpabilidad, entonces era difícil explicar que la construcción de la falta de cuidado se dividiera ya en un cuidado objetivo, dependiente de un estándar abstracto, y un cuidado subjetivo, el cual atiende a las capacidades específicas del autor. En otras palabras, la imprudencia entendida de esta forma incorporaría elementos objetivos en la categoría puramente subjetiva de la culpabilidad alterando la estructura del sistema causalista. Por el contrario, con el advenimiento de un sistema finalista, que modifica radicalmente la comprensión de la estructura del delito, la postura generalizadora resulta sumamente cómoda. En tal sentido, se sostiene que el cuidado debía entenderse como un concepto objetivo y normativo sin necesidad de aludir al cuidado que el sujeto concretamente considerado podía ejercer, sino sólo el cuidado necesario en el tráfico ${ }^{70}$. Y ese cuidado necesario depende de que los efectos de la acción fueran cognoscibles en un juicio inteligente, esto es, coincidentes con la conducta seguida por un hombre razonable y prudente en la situación del autor ${ }^{71}$.

\subsection{Los problemas de una posición generalizadora.}

Ahora bien, puede parecer que un estándar objetivo generalizado funciona bastante bien en abstracto sin embargo esconde varias deficiencias que se evidencian en concreto. Volvamos al caso $\left(\mathrm{C}_{1}\right)$ del médico A que realiza una intervención quirúrgica sin darse cuenta que la técnica utilizada es errónea causando la muerte de P. ¿Cómo afirmamos la imprudencia desde una posición generalizadora? Tendríamos que señalar que la conducta de A infringe el estándar de cuidado construido con conocimientos y capacidades generales o, que es lo mismo, que un sujeto abstracto hubiese verificado las condiciones del paciente antes de operarlo. Pero aquí surge la primera interrogante: ¿el hombre razonable utilizado es un médico? Y la respuesta sensata sería afirmativa puesto que el estándar apunta a lo realizado por un hombre abstracto en la posición del autor, y aquí A es médico de forma que sería tramposo excluir esta condición. Lo anterior resulta fundamental, además, porque si el estándar objetivo no hiciera referencia a (lo que sabe y puede) un médico, sino a un hombre razonable a secas, sería difícil justificar ya su sola participación en una intervención

\footnotetext{
${ }^{69}$ VAN WEEZEL, Álex, "Parámetros para el enjuiciamiento de la infracción al deber de cuidado en los delitos imprudentes“, Revista Chilena de Derecho, vol. 26, N 2 (1999), p. 324, quien considera que al asumir un deber objetivo de cuidado sólo se está a conocimientos y capacidades generales, tanto si en concreto se puede más, como si en concreto se puede menos. Y si el sujeto estaba bajo el estándar, entonces el deber obligaba a abstenerse de realizar la acción.

${ }^{70}$ TORÍO, "El deber", cit. nota n' 27, p. 29, donde cita a Welzel.

${ }^{71}$ TORÍO, "El deber", cit. nota ${ }^{\circ}$ 27, p. 30, donde cita a Welzel.
} 
REYES, Italo. "Sobre la construcción de la exigencia de cuidado".

quirúrgica. Por tanto, la determinación del actuar imprudente de $\mathrm{A}$ en $\mathrm{C}_{1}$ se observaría al entender que cualquier médico hubiese revisado la ficha de $\mathrm{P}$ antes de operarlo.

Sin embargo, la medicina incorpora un número amplio de especialidades, de manera que valga una primera modificación del caso: $\left(C_{2}\right)$ A es un neurocirujano que debe realizar una intervención que requiere habilidades y conocimientos específicos de esa especialidad, fallando en una de esas técnicas causando la muerte de P.

La pregunta, ahora, es si el estándar tendría que incorporar los conocimientos y capacidades de un neurocirujano o, simplemente, mantener la respuesta a $\mathrm{C}_{1}$, es decir, enfocarse en las capacidades promedio de cualquier médico. O sea, desde la posición generalizadora, cuando nos preguntamos si la conducta de $\mathrm{A}$ en $\mathrm{C}_{2}$ fue imprudente, ¿la analizamos desde lo que un médico (general) podía y sabía hacer o desde lo que un neurocirujano podía y sabía hacer? Y la respuesta es de todo menos sencilla. Existirán dos alternativas: primero, que el estándar relevante siga siendo el médico (general) con el objetivo de evitar cualquier subjetivización del mismo; o segundo, aceptar la especialización médica arguyendo que se mantiene como categoría objetiva al referirse a las capacidades generales de la categoría de neurocirujano y no de un neurocirujano en particular. Es decir, se propone diferenciar objetivamente entre lo que le corresponde a un médico general y lo que le corresponde a un médico especialista, en este caso un neurocirujano, estableciendo por tanto un estándar diverso en ambos casos. La primera alternativa de solución se enfrenta con el difícil problema de que cualquier intento en concretar el estándar en algo más preciso que el mero hombre razonable implicaría una subjetivización, de forma que la sola consideración de la profesión médica ya se vería excluida. Aquello no resulta sensato pues parece evidente que el ordenamiento exige de forma diferente a quien es médico y a quien no lo es ${ }^{72}$.

Por lo tanto, la segunda alternativa parecería que responde adecuadamente a las críticas y mantiene las premisas de la posición generalizadora, aceptando como categoría objetiva relevante la de neurocirujano. Sin embargo, es posible seguir precisando el caso: $\left(\mathrm{C}_{3}\right) \mathrm{A}$ forma parte de un selecto grupo de cinco neurocirujanos que, debido a sus investigaciones en conjunto, son los únicos que cuentan con las capacidades y los conocimientos necesarios para realizar la intervención quirúrgica que puede salvar la vida al paciente, y que justamente A se equivoca por cansancio en uno de los movimientos que sólo ellos cinco pueden realizar.

Esta categoría de neurocirujanos de excelencia, ¿permite reformular nuevamente el estándar? Porque si asumimos que ningún otro de los neurocirujanos del mundo tiene las condiciones para realizar la operación, entonces parece incorrecto mantener el esquema previo al no ser pertinente en el contexto actual; es decir, si el estándar relevante sigue siendo simplemente el del neurocirujano entonces a esos cinco expertos se les estaría exigiendo mucho menos de lo que pueden e, incluso, la conducta de A no podría entenderse como imprudente porque para un neurocirujano promedio la intervención era completamente inaccesible. Por tal razón, pareciera que nuevamente sería necesario actualizar el estándar, de manera que el comportamiento modelo fuera el correspondiente a

\footnotetext{
${ }^{72}$ Lo que se expresaría con claridad en normas de sanción diferenciadas en el artículo 490 para un sujeto activo cualquiera y el artículo 492 para un sujeto activo con conocimientos médicos.
} 
Polít. crim. Vol. 10, No 19 (Julio 2015), Art. 3, pp. 56-91.

[http://www.politicacriminal.cl/Vol_10/n_19/Vol10N19A3.pdf]

las capacidades y conocimientos de esos cinco neurocirujanos. De esta forma, A actúa con falta de cuidado porque un neurocirujano promedio calificado hubiese tomado ciertas precauciones mínimas o simplemente se hubiese abstenido de operar en las condiciones de agotamiento físico en que se encontraba A. Nótese que aquí ya es delicado seguir hablando de capacidades generales o promedios puesto que hemos concretado el estándar hasta hacer referencia simplemente a cinco personas. Para hacer evidente el problema, piénsese en la última reformulación del caso: $\left(\mathrm{C}_{4}\right)$ solamente A tiene las habilidades y conocimientos para realizar la intervención. Si fuéramos coherentes con el argumento que permite concretar el estándar, entonces no existirían razones para no atender precisamente a las habilidades y conocimientos de A.

De esta forma, la referencia a las capacidades promedio de un hombre cualquiera para la determinación del cuidado exigido, puede ser una forma de resolver casos sencillos, en donde no existen dudas en que el sujeto concreto cuenta con las capacidades y conocimientos que corresponden a los generales. Sin embargo, cuando la posibilidad de analizar los peligros y dificultades de una situación dependen de conocimientos y capacidades especializadas, entonces el recurso a un estándar puramente promedio falla. Para ello, se requiere sostener "sectores del tráfico"73 que si bien pretenden conservar un carácter puramente objetivo -distinguiendo, por ejemplo, entre el sector del médico general y el del médico especialista- terminan siendo insuficientes cuando las capacidades y conocimientos superiores asumen específica relevancia en un caso concreto.

\subsubsection{Primera propuesta de solución: Incluir conocimientos especiales.}

Esta dificultad también ha sido identificada por los mismos defensores de la posición generalizadora, de ahí que tradicionalmente se ha propuesto como solución que los conocimientos especiales deben ser tenidos en cuenta para la determinación del cuidado exigido, aunque las capacidades especiales permanecen excluidas. ${ }^{74}$ En otras palabras, se pretende que la incorporación de los conocimientos especiales del sujeto en la construcción del estándar venga a establecer con mayor precisión la exigencia de cuidado del agente.

No obstante, esta posición generalizadora corregida plantea dos dificultades inmediatas. En primer lugar, se hace una compleja diferencia entre conocimientos y capacidades, basada en un criterio meramente fenoménico, o sea, los conocimientos harían referencia a elementos cognitivo-intelectuales y las capacidades a elementos físicos. En teoría, entonces, la natación sería una capacidad porque se manifiesta en una actividad física y el lenguaje alemán sería un conocimiento puesto que implica una actividad intelectual. Sin embargo, es sumamente complicado trazar una frontera insalvable entre ambos conceptos, puesto que ya desde el lenguaje cotidiano parece observarse una conexión entre la capacidad y el conocimiento, en el sentido que este último es el fundamento del ejercicio de la primera. Por ejemplo, entre "alguien sabe alemán" y "alguien puede hablar alemán": nadie puede (ejercer la actividad de) hablar alemán sin saber previamente alemán, de la misma forma

\footnotetext{
${ }^{73}$ ROXIN, Claus, Derecho Penal, parte general. Tomo I. Madrid: Civitas, 1997, pp. 1009 y 1017; CORCOY, "El delito imprudente", cit. nota ${ }^{\circ} 13$, pp. 142 s.

${ }^{74}$ Véase BURKHARDT, "Conducta típica", cit. nota $\mathrm{n}^{\circ}$ 29, p. 158 y ZUGALDÍA, "La infracción”, cit. nota $\mathrm{n}^{\mathrm{o}} 67, \mathrm{p} .328$.
} 
REYES, Italo. "Sobre la construcción de la exigencia de cuidado".

que nadie puede (ejercer la actividad de) nadar sin saber previamente nadar ${ }^{75}$. En el caso del médico, entonces, para realizar una intervención quirúrgica, o sea, ser capaz de ejecutarla, debe saber el procedimiento y la técnica correspondiente. Lo anterior implica una conexión conceptual entre la capacidad y el conocimiento ${ }^{76}$ que justificaría fuerte reticencia ante una tesis que las distancia y las trata como conceptos independientes, incorporando una y excluyendo otra.

En segundo lugar, la incorporación de los conocimientos especiales pone en duda la aseveración de un estándar objetivo promedio, en el sentido de una anticipación de elementos subjetivos que sólo serían pertinentes en ámbito de culpabilidad. Es decir, si la finalidad de la posición generalizadora está en mantener en el injusto un concepto de imprudencia puramente objetiva, la inclusión de un elemento subjetivo en la construcción del estándar de imprudencia parecería subvertir tal propósito ${ }^{77}$. Ante ello, se contra argumenta que "la inclusión de los conocimientos del autor no es un anticipo de lo subjetivo, sino la construcción de un juicio objetivo de peligro ajustado a peculiaridades más o menos generalizadas" ${ }^{, 78}$. Aún así, el interés en los conocimientos especiales se observa cuando el juzgador objetivo promedio es incapaz de valorar el riesgo que sí puede valorar el autor individual, lo que ya permite cuestionar si el juicio de peligro basado en el conocimiento de la realidad de una persona modelo es adecuado para la construcción de la exigencia de cuidado ${ }^{79}$.

Pero además, la incorporación de los conocimientos especiales sólo opera en un sentido, ya que sólo adquiere aplicación allí donde perjudica al sujeto, es decir, justifica la sanción en los casos que quedarían impunes bajo el estándar promedio general. De tal manera, se pretende corregir las lagunas de punibilidad exigiendo el ejercicio de todo aquel conocimiento que sobrepasa al promedio en la realización de la conducta ${ }^{80}$. No obstante, y debido a su menor notoriedad, no se resuelven, en el ámbito del injusto, los casos de excesos de punibilidad: situaciones en las que el sujeto tiene capacidades y conocimientos inferiores al promedio. Y lo más grave es que, aún cuando la posición generalizadora pretende que tales casos sean resueltos en sede de culpabilidad, resulta problemático que todos ellos puedan ser dogmáticamente incorporados como causas de inculpabilidad o exculpación $^{81}$, de modo que existe la posibilidad que la incapacidad del sujeto en el

\footnotetext{
${ }^{75}$ En el ámbito de imputación a título de dolo, la relación entre capacidad y conocimiento resulta aún más clara. Al afirmar dolo se afirma que el sujeto tuvo la capacidad para evitar el comportamiento debido a que conoció las circunstancias físicas de su actuar. La principal diferencia con el "saber cotidiano" es que el lenguaje de la imputación es radicalmente contrafáctico pues lo que interesa es determinar la contradicción entre la voluntad del sujeto y el ordenamiento.

${ }^{76}$ En el mismo sentido, CORCOY, "El delito imprudente", cit. nota n 13, p. 132, 143 y ss.

77 En contra, ROJAS, Luis Emilio, “Lo subjetivo en el juicio de imputación objetiva: ¿Aporía teórica?”, Revista de Derecho U. Austral vol. XXIII, n 1 (2010), pp. 244 y ss., 249 y ss., quien, recurriendo a las formulaciones originales de la teoría de la imputación objetiva de Larenz y Honig, sostiene que lo fundamental para esta teoría es determinar con precisión lo que corresponde a la voluntad del sujeto y lo que corresponde al mero acaso. Ello no se opondría a la utilización de conocimientos especiales en una imputación meramente objetiva.

${ }^{78}$ Tal argumento es descrito en BURKHARDT, "Conducta típica”, cit. nota n ${ }^{\circ} 29$, p. 159.

${ }^{79}$ BURKHARDT, “Conducta típica”, cit. nota n' 29, p. 164.

${ }^{80}$ VAN WEEZEL, "Parámetros", cit. nota n ${ }^{\circ} 69$, p. 329.

${ }^{81}$ VAN WEEZEL, "Parámetros", cit. nota n 69, pp. 325 y 329.
} 
Polít. crim. Vol. 10, № 19 (Julio 2015), Art. 3, pp. 56-91.

[http://www.politicacriminal.cl/Vol_10/n_19/Vol10N19A3.pdf]

seguimiento de un estándar inalcanzable no sea analizada. Si ese es el caso estamos infringiendo la máxima básica ultra posse nemo obligatur puesto que imponemos una pena a un sujeto que no estaba en condiciones de evitar la infracción de la exigencia de cuidado.

\subsubsection{Segunda propuesta de solución: Utilizar la estructura del delito de omisión impropia.}

Por otro lado y con la finalidad de solucionar las lagunas de punibilidad como los casos más evidentes en que una posición generalizadora entrega soluciones inapropiadas, ciertos partidarios han acudido al delito de omisión impropia. Así, se plantea que, desde una postura generalizadora, un sujeto que no ejecuta sus facultades excepcionales no configuraría un delito comisivo imprudente, puesto que sus capacidades superiores no serían consideradas en el estándar de cuidado. Sin embargo, en ese mismo caso, se estaría en presencia de un delito omisivo impropio (imprudente) puesto que el sujeto se encuentra en posición de garante que lo obliga al ejercicio de todas sus habilidades para evitar el resultado lesivo ${ }^{82}$. Por ejemplo, el cirujano que tiene habilidades especiales pero que no las ejerce y el paciente fallece, no podría reprochársele un delito comisivo imprudente puesto que no infringe el estándar de cuidado fundado en un cirujano abstracto con capacidades generales. Sin embargo, dado que está en posición de garante (por injerencia, confianza especial, deber institucional de salvamento o la que sea), debe evitar la muerte del paciente para lo cual se le exige el ejercicio de todas sus habilidades. De forma que si se comporta imprudentemente, confiando que el resultado de muerte no se produjera, entonces configuraría un cuasidelito de homicidio omisivo impropio.

No obstante, acudir a un concepto de omisión imprudente para salvaguardar una posición generalizadora resulta sistemáticamente equivocado porque implica utilizar un concepto diferente de cuidado entre el delito comisivo y el omisivo ${ }^{83}$. Es decir, la falta de cuidado se construiría bajo criterios distintos si asumimos una perspectiva comisiva u omisiva de la conducta. Ello implica una discrepancia conceptual que carece de toda justificación ya que no existen razones para sostener que el contenido de la exigencia de cuidado dependa de la clase de delito que se analiza.

\subsection{Una posición generalizadora "moderada".}

Por su parte, Claus Roxin plantea que la determinación de la imprudencia no requiere otros criterios más allá de los que entrega la imputación objetiva, de modo que al autor "no se le reprocha haber omitido algo sino el haber creado un peligro no amparado por riesgo permitido y sí abarcado por el fin de protección del tipo, que se ha realizado en el resultado típico". ${ }^{84}$ Pero en lo que se refiere al contenido del estándar de cuidado, la teoría de la imprudencia de Roxin opera como una postura intermedia entre generalizadores e individualizadores.

\footnotetext{
82 VAN WEEZEL, "Parámetros", cit. nota n 69, pp. 326 y ss., donde simplemente explica la defensa generalizadora para luego optar por una postura individualizadora

${ }^{83}$ VAN WEEZEL, "Parámetros", cit. nota n 69, p. 327 quien entiende a la asimetría de la solución como la comprobación de lo insostenible de la construcción.

${ }^{84}$ ROXIN, Derecho Penal, cit. nota n ${ }^{\text {7 }} 73$, p. 1000.
} 
REYES, Italo. "Sobre la construcción de la exigencia de cuidado".

Así, Roxin parte argumentando desde una teoría generalizadora pero evidenciando las dificultades cuando el agente posee capacidades o conocimientos que no se corresponden con los del baremo objetivo. Ante ello, propone que:"las capacidades inferiores a la media no pueden excluir el tipo y la antijuricidad, mientras que las capacidades superiores a la media deben sin embargo emplearse. Por tanto, se ha de generalizar hacia 'abajo' e individualizar hacia 'arriba", 85 . En tal sentido, se plantea una alternativa ecléctica que utiliza los planteamientos de la posición generalizadora ante situaciones inferiores al promedio y los de la posición individualizadora ante situaciones superiores ${ }^{86}$.

Por un lado, Roxin sostiene que la individualización hacia arriba es enteramente necesaria en atención a tres argumentos. Tales argumentos son también razones para asumir una posición individualizadora, como la aquí defendida. Así, en primer lugar, se plantea que un sujeto con habilidades superiores está obligado a hacer uso de ellas, de modo que cuando por negligencia no lo hace, debe ser sancionado ${ }^{87}$. Además, se plantea que los delitos de omisión (impropia) también incorporan las capacidades especiales en la determinación del deber de acción del garante, de modo que no puede suceder en el delito comisivo algo diferente $^{88}$. Y, finalmente, que la postura generalizadora, para responder a este problema, se ve obligada a recurrir a la construcción de restringidos sectores del tráfico que no vienen sino a minar sus propias premisas al constituir una individualización del estándar ${ }^{89}$.

Ahora bien, respecto a las capacidades inferiores, Roxin plantea dos argumentos que justifican su exclusión y la asunción de un estándar objetivo promedio. El primer argumento, que podríamos denominar sistemático, acude a un límite infranqueable entre el injusto y la culpabilidad, en el sentido que aquél se vincula a los baremos de la creación del peligro y del fin de la protección, lo que resulta indiferente a la individualidad del autor; mientras que la culpabilidad sería la categoría que enmarca las situaciones de imposibilidad individual de actuar de otro modo ${ }^{90}$. Es decir, tomar en consideración las capacidades inferiores a la media del sujeto conllevaría un caos entre injusto y culpabilidad. A pesar que es correcto que una posición individualizadora enfrenta el difícil desafío de justificar si la apreciación concretizada del deber de cuidado no termina por subjetivizar el estándar -lo cual se intentará defender más adelante- continúa siendo posible postular una diferencia entre el injusto imprudente y la culpabilidad, puesto que el primero debe fundarse en (la infracción de) un estándar objetivo de cuidado que, empero, se construye en base a las capacidades y conocimientos del sujeto. No se considera en el injusto, entonces, al agente individual sino que se dota al estándar de las características del sujeto que son jurídico penalmente relevantes para la determinación de la exigencia de cuidado.

\footnotetext{
${ }^{85}$ ROXIN, Derecho Penal, cit. nota no 73 , p. 1015.

${ }^{86}$ De acuerdo con ROSAS, “La delimitación”, cit. nota $n^{\circ} 28$, p. 3, una posición ecléctica como la de Roxin igualmente debiera ser entendida como individualizadora (o, en sus términos, subjetivo-individualizadora).

${ }^{87}$ ROXIN, Derecho Penal, cit. nota ${ }^{\circ}$ 73, p. 1017. Respecto de los conocimientos especiales, Roxin entiende que una posición generalizadora los incorpora sin discusión, excluyendo simplemente las capacidades especiales, de modo que es ese agregado el que está necesitado de justificación.

${ }^{88}$ ROXIN, Derecho Penal, cit. nota no 73, p. 1017.

${ }^{89}$ ROXIN, Derecho Penal, cit. nota no 73, p. 1018.

${ }^{90}$ ROXIN, Derecho Penal, cit. nota ${ }^{\circ} 73$, p. 1015.
} 
Polít. crim. Vol. 10, No 19 (Julio 2015), Art. 3, pp. 56-91.

[http://www.politicacriminal.cl/Vol_10/n_19/Vol10N19A3.pdf]

Un segundo argumento, que podríamos llamar lógico, se refiere a la tradicional crítica de los partidarios de una concepción individualizadora (y que ya hemos utilizado aquî): si una posición generalizadora excluye las capacidades inferiores al promedio entonces aquel sujeto que cuenta con tales capacidades mínimas estaría obligado a evitar una conducta que le sería imposible de evitar. En respuesta, Roxin señala que este argumento no puede aceptarse ya que "la norma se dirige a todos" al establecer un cuidado mínimo esperable y que obliga a la abstención cuando el sujeto carece de las facultades pertinentes (culpa por asunción $)^{91}$. No obstante, el argumento de Roxin es problemático, pues resulta trivialmente evidente que la norma está dirigida a todos, pero de ello no se sigue la imposibilidad de considerar cualidades personales del autor. Es decir, que se tome en cuenta la misma norma no implica que la imputación sea realizada exactamente igual para todos los sujetos sometidos a ella: tal imputación dependerá de la especial situación en la que se encuentra el sujeto, pues las reglas de imputación -dolo e imprudencia- examinan con detención las circunstancias de hecho específicas para determinar la capacidad de evitación del resultado lesivo. Las normas se dirigen a todos por igual pero se concretan de manera diferente dependiendo del contexto de actuación, en donde la referencia a las capacidades del autor tiene que ser un elemento relevante a considerar.

Y en lo que respecta a la culpa por asunción, Roxin tampoco está en lo correcto. Porque supone que quien tiene capacidades y conocimientos inferiores a la media tiene la obligación de abstenerse de ejecutar una conducta para la cual no está preparado. Sin embargo eso es simplificar el problema. Porque para fundar una obligación de abstención debe ser posible aseverar la posibilidad del sujeto de darse cuenta que carece de las condiciones que la actividad requiere y que, por tanto, le obliga a abstenerse. No obstante, en estos casos, la referencia a capacidades y conocimientos inferiores implica la imposibilidad de que ese sujeto se hubiese incluso percatado de su ineptitud en la ejecución del comportamiento. Es, de nuevo, trivialmente correcto que quien carece de capacidades debe abstenerse, de forma que si emprende la actividad y se produce un resultado antinormativo deberá responder a título de imprudencia. Pero para ello debe ser posible afirmar que las habilidades del sujeto le hubieran permitido notar su propio déficit. Si era imposible, dada sus mínimas capacidades, incluso percatarse de esa situación, entonces ¿cómo podríamos exigirle que se abstuviera? Hacerlo sería simplemente fundar una exigencia de cuidado imposible de cumplir en la práctica.

\subsection{Una posición individualizadora.}

Desde la perspectiva opuesta, una posición individualizadora prescinde de cualquier recurso a conocimientos y capacidades promedios, concentrándose en lo que el específico individuo que está siendo imputado conocía y podía. No interesa, entonces, que un hombre abstracto con conocimientos y capacidades generales hubiese ejercido un nivel de cuidado que el autor en efecto no ejerció, ya que la exigencia de cuidado requiere integrar los conocimientos y capacidades del autor con la finalidad de determinar si ese preciso sujeto no aseguró su capacidad de seguimiento futuro de la norma estando obligado a ello ${ }^{92-93}$.

\footnotetext{
${ }^{91}$ ROXIN, Derecho Penal, cit. nota n ${ }^{\circ} 73$, p. 1016.

92 De acuerdo con HERNÁNDEZ, "Comentario", cit. nota $\mathrm{n}^{\circ} 27$, p. 113 y s., la doctrina chilena mayoritaria asumiría un parámetro individualizador pues la determinación de la exigencia de cuidado debe tomar en
} 
REYES, Italo. "Sobre la construcción de la exigencia de cuidado".

Hablar de imprudencia es hablar de la posibilidad de que el sujeto evite quedar en una situación de incapacidad de evitar la infracción de la norma; es decir, que si se hubiese comportado de acuerdo al cuidado esperado y exigido, la realización del tipo objetivo le hubiese sido evitable. Nótese, por tanto, lo relevante que resulta la referencia al sujeto ya para explicar el concepto de imprudencia: la exigencia del actuar cuidadoso no está descontextualizada sino que depende de la posición que asume el autor. Si la imputación a título de imprudencia pretende examinar la posibilidad de actuación cuidadosa del sujeto para asegurar su capacidad posterior de seguir la norma, entonces lo que el sujeto puede y sabe es fundamental para determinar el nivel de cuidado exigible. Dado que la norma de comportamiento se dirige a individuos, ésta sólo puede seguirse individualmente ${ }^{94}$. La expectativa normativa, entonces, no es simplemente un actuar cuidadoso sino un actuar cuidadoso en una situación determinada para un sujeto determinado, lo cual implica tomar en cuenta, por supuesto, sus conocimientos y habilidades especiales ${ }^{95}$.

Por eso, un reemplazo de lo que el autor sabe y puede por lo que una figura abstracta sabe y puede implica un reemplazo de quien está siendo imputado en el sentido que se estaría determinando la responsabilidad de esa figura abstracta y no del autor. "Que una persona distinta del autor se hubiere comportado de un modo diferente a éste, no podría jamás fundamentar el reproche de que el autor se ha comportado incorrectamente" 96 .

Ahora bien, no puede rechazarse a priori que las capacidades y conocimientos promedios puedan llegar a ser relevantes en la determinación del cuidado exigible, pues es perfectamente posible que las capacidades y conocimientos concretos del sujeto también sean promedios ${ }^{97}$. Y esto resulta bastante común pues lo habitual es que las condiciones personales no sean ni superiores ni inferiores a la media. Probablemente ésta es una de las razones de la fortaleza de una postura generalizadora: usualmente entrega una solución

cuenta las circunstancias concretas, lo que incluiría la posesión de conocimientos especiales. No obstante, también es una idea bastante general que ciertas capacidades no consideradas en el injusto deben ser revisadas en culpabilidad. En tal sentido, la doctrina chilena sólo asumiría ciertas consecuencias de la posición individualizadora. Para una revisión detallada de la exigencia de cuidado en contexto médico, véase MARTÍNEZ, Marco, "La graduación del deber de cuidado en el delito culposo por actos de mala praxis médica: un análisis dogmático, jurisprudencial y económico”, Política Criminal vol. 6, n¹2 (2011), pp. 239 ss., quien recurre a una posición que incorpora los conocimientos especiales del médico en la determinación de su falta de cuidado.

${ }^{93}$ La jurisprudencia nacional no ha analizado en concreto la controversia entre una posición individualizadora o una generalizadora. Sin embargo, puede señalarse que, implícitamente, ésta suele considerar los conocimientos del sujeto para determinar si se ha infringido el deber de cuidado. Una excepción al no tratamiento específico del problema lo constituye la sentencia de la Corte de Apelaciones de La Serena, 21.12.2009, rol 363-09, en donde se señala: "Debe tenerse en cuenta que en el delito culposo concurren elementos subjetivos, lo que necesariamente implica, entonces, la existencia de un determinado conocimiento de la acción que se desarrolla y los riesgos que ella implica, porque de otra manera el acontecimiento carecería de significación jurídico penal, razón que permite observar la necesidad de tener en consideración los conocimientos especiales del sujeto activo, así como sus específicas particularidades". (El destacado es mío)

${ }^{94}$ KINDHÄUSER, ¿Qué es la imprudencia?, cit. nota no 5, p. 224.

95 En el mismo sentido, OVALLE, “Imprudencia y cognición”, cit. nota n 6, p. 5.

${ }^{96}$ KINDHÄUSER, El tipo subjetivo, cit. nota ${ }^{\circ} 1$, p. 19.

${ }^{97}$ KINDHÄUSER, ¿Qué es la imprudencia?, cit. nota no 5, p. 223. Asimismo, KINDHÄUSER, El tipo subjetivo, cit. nota $\mathrm{n}^{\mathrm{o}} 1$, p. 21. 
Polít. crim. Vol. 10, No 19 (Julio 2015), Art. 3, pp. 56-91.

[http://www.politicacriminal.cl/Vol_10/n_19/Vol10N19A3.pdf]

correcta, pero no debido a lo verdadero de sus postulados sino porque contingentemente las capacidades y conocimientos del sujeto se corresponden con la media. Allí donde no existe esa correspondencia, empero, quedan en evidencia los déficit tanto de exceso como de falta de punibilidad.

En tal sentido, desde un punto de vista práctico, la principal ventaja de una postura individualizadora es que desaparecen las situaciones caracterizadas, bajo un modelo generalizador, como excesos y lagunas de punibilidad. Una postura generalizadora se ve obligada a incluir modificaciones para responder a los casos de lagunas de punibilidad, pues el resultado coherente con sus premisas conllevaría un vacío de responsabilidad de los más dotados -por el solo hecho de serlos- que parece inaceptable y contraintuitivo. Nótese, empero, que los casos de exceso de punibilidad son completamente pasados por alto en el ámbito del injusto, afirmándose su exclusión sólo en sede de culpabilidad, aún cuando resultase imposible el seguimiento de la norma por parte del autor. Desde una posición individualizadora, por el contrario, al entender la imprudencia como un uso deficitario de los conocimientos y capacidades del autor, entonces no existen casos ni de exceso ni de laguna de punibilidad: la responsabilidad del sujeto depende única y exclusivamente de sus capacidades, no lo que podía o sabía un modelo promedio; simplemente se imputa en virtud de la capacidad específica del autor.

Debe tenerse presente, eso sí, que postular la inclusión de los conocimientos y capacidades especiales en la construcción de la exigencia de cuidado no puede implicar "borrar con el codo" las conclusiones ya alcanzadas previamente. Es decir, que una postura individualizadora asuma de entrada que lo único relevante para determinar el proceder cuidadoso es lo que podía y sabía hacer el sujeto imputado, no significa renunciar a un estándar objetivo en la fijación del cuidado exigido, sino simplemente dotarlo del contenido adecuado. De tal modo, la determinación de la imprudencia sigue siendo normativa pero enfocada en los conocimientos y capacidades del sujeto que actúa. Para clarificar el punto, puede ser útil volver a nuestro ejemplo del médico: A realiza una intervención quirúrgica sin revisar la ficha médica del paciente por lo que aplica una técnica inadecuada que causa su muerte. Lo cuidadoso se determinará en atención a lo que un ciudadano fiel a derecho (estándar objetivo) con los conocimientos y capacidades de A (modelo individualizador) hubiese realizado en el contexto planteado, de modo que si éste hubiese tomado una serie de precauciones para evitar el accidente, las cuales no fueron ejecutadas por A, entonces su conducta infringe la exigencia de cuidado que el ordenamiento le dirige en cuanto destinatario leal a derecho, configurándose, entonces, el injusto subjetivo del delito.

\subsection{Críticas a la posición individualizadora.}

Sostener una posición individualizadora implica responder, por lo menos, a tres críticas básicas: la renuncia del estándar objetivo por medio de una subjetivización de todo el modelo de la imprudencia; la sucesiva desigualdad de trato que traería aparejada una construcción que incluya los conocimientos y capacidades de los sujetos; y la irrelevancia que debiese otorgársele a los conocimientos especiales desde las perspectivas de los roles sociales. En lo que sigue, revisaremos brevemente cómo pueden responderse adecuadamente tales interrogantes. 
REYES, Italo. "Sobre la construcción de la exigencia de cuidado".

\subsection{1. ¿Subjetivización del modelo?}

Como anticipábamos, una postura individualizadora tiene que dar respuesta a la siguiente interrogante: si la incorporación de los conocimientos y capacidades del individuo en la construcción de la exigencia de cuidado no termina por subjetivizarla totalmente ${ }^{98}$. En otras palabras, un opositor al modelo individualizador sostendría que dotar al estándar objetivo de las capacidades y conocimientos específicos del autor parece simplemente una excusa para volver a poner el foco en ese específico sujeto y renegar, por tanto, un estándar objetivo en la determinación del cuidado debido. En definitiva, lo cuidadoso del comportamiento estaría definido por lo que el mismo sujeto considerase cuidadoso, tesis que no diferiría sustancialmente de los modelos sicológicos que criticábamos férreamente al inicio de este artículo (y que están hace mucho tiempo superados).

La crítica es prima facie razonable pues el problema está en si podemos seguir hablando de estándar objetivo luego de incluir las habilidades y conocimientos del concreto autor que se imputa. La respuesta está, no obstante, en una adecuada comprensión de la exigencia de cuidado.

El recurso al ciudadano fiel a derecho en contexto de imputación permite determinar si el sujeto, por medio de su comportamiento, ha levantado una voluntad contraria al ordenamiento merecedora de pena por oponerse a la voluntad general del derecho expresada en las normas de comportamiento penales. En tal sentido, discutir sobre la infracción de la exigencia de cuidado en un contexto específico implica determinar las expectativas legítimas del ordenamiento respecto del sujeto y si se vieron defraudadas en el caso concreto, o sea, si se comportó de una manera diferente a lo que hubiera realizado un ciudadano fiel a derecho. Esas expectativas normativas se concretan, según lo aquí sostenido, en cómo se hubiese comportado un participante cuidadoso en el tráfico en la misma situación del autor, esto es, con sus capacidades y conocimientos. De tal manera, la imprudencia presupone una figura estándar en cuanto a las expectativas que el ordenamiento dirige a la conducta del autor, pero siempre concretadas en los particulares conocimientos y capacidades que el sujeto individual tenía al momento de actuar ${ }^{99}$.

De ahí que "la imprudencia es un uso deficitario de la concreta capacidad intelectual de evitación del autor individual que se valora como descuidado según estándares objetivos"100. Sin recurrir al estándar objetivo no podríamos desentrañar la expectativa normativa orientada al sujeto puesto que ella supone un comportamiento cuidadoso, es decir, se espera que el sujeto realice una determinada acción que en definitiva sea cuidadosa. Pero como precisamente estamos tratando de determinar si el comportamiento fue o no cuidadoso, tenemos que comparar lo efectivamente realizado por el sujeto con lo que el ordenamiento esperaba que realizara para asegurar su capacidad de seguimiento de la norma. Tal comparación requiere de la utilización de un estándar objetivo, pero siempre

\footnotetext{
98 VAN WEEZEL, "Parámetros", cit. nota n o 69, p. 325.

${ }^{99}$ Véase KINDHÄUSER, El tipo subjetivo, cit. nota ${ }^{\circ}$ 1, p. 20.

${ }^{100}$ KINDHÄUSER, El tipo subjetivo, cit. nota $n^{\circ} 1$, p. 20.
} 
Polít. crim. Vol. 10, № 19 (Julio 2015), Art. 3, pp. 56-91.

[http://www.politicacriminal.cl/Vol_10/n_19/Vol10N19A3.pdf]

referido a lo que podía y sabía el autor ya que es su responsabilidad la que tratamos de zanjar $^{101}$.

Que tengamos que recurrir a un estándar normativo entraña que el concepto de cuidado no queda a disposición de lo que el mismo autor considera que es cuidadoso. Por el contrario, significa que el contenido del cuidado se define por igual para todos mediante conceptos universalizables que no dependen de la subjetividad del agente, a saber: lo que un ciudadano fiel a derecho hubiese realizado ${ }^{102}$. Pero lo que se entienda como cuidadoso siempre tiene que depender del contexto preciso en que se actúa y de las habilidades y conocimientos que se tienen. De tal forma, dotar de las habilidades y conocimientos del autor al estándar objetivo se deriva de una teoría seriamente comprometida con el principio ultra nemo posse obligatur, esto es, que las obligaciones de un agente están directamente relacionadas con sus capacidades, lo que significa: para afirmar cualquier obligación (como por ejemplo, la exigencia de cuidado) debe tomarse en consideración la capacidad del agente en cuestión.

\subsection{2. ¿Desigualdad de trato?}

La segunda crítica consistiría en que atender específicamente a la constitución cognitiva del autor implica una infracción de la igualdad de trato, puesto que la severidad de exigencia de cuidado dependería del sujeto a imputar. Es decir, quien sabe más estaría obligado a ser más cuidadoso que quien ostenta conocimientos generales, siendo responsable por situaciones que para este último resultarían impunes. Esa discrepancia atentaría en contra de un imperativo jurídico básico pues la exigencia de cuidado sería más intensa para el intelectualmente dotado, ya que la misma norma obligaría a algunos a $\mathrm{X}$ mientras que a otros a X+1. O sea, respecto del mismo contexto de actuación, el nivel de cuidado exigido variará según la constitución de cada sujeto. En síntesis, la individualización del estándar sería injusta e, incluso, ineficaz: injusta porque el nivel de cuidado se basaría en un diferencia cognitiva; e ineficaz porque desincentivaría el incremento de conocimientos ya que vendría aparejado a un deber de cuidado más intenso.

Sin embargo, esta crítica carece de asidero puesto que la tesis defendida no toma en consideración capacidades o conocimientos especiales potenciales, sino solamente actuales $^{103}$. Efectivamente está fuera de lugar exigir la aplicación de habilidades que el sujeto está incapacitado de ejecutar, pero que podría hacerlo en otro momento. Ello implicaría un incremento injusto de las exigencias de cuidado, porque aquellos con una constitución física o cognitiva sobre la media estarían obligados a asegurar su utilización en todo caso. Por el contrario, sólo interesan las capacidades actuales de manera que el sujeto especialmente capaz también puede despreocuparse de la subsistencia de sus capacidades

${ }^{101}$ KINDHÄUSER, ¿Qué es la imprudencia?, cit. nota nº 5, p. 224: "la figura estandarizada de cuidado se identifica con el destinatario de la norma leal a derecho y capaz de decisión racional, que es presupuesto por el fin de la pena, dotado de la constitución física e intelectual del autor".

${ }^{102}$ En el mismo sentido, CORCOY, "El delito imprudente", cit. nota $\mathrm{n}^{\circ} 13$, pp. 137, quien distingue con claridad que "individualizar no significa subjetivizar". Véase supra, capítulo 1.

${ }^{103}$ KINDHÄUSER, El tipo subjetivo, cit. nota $n^{\circ}$ 1, p. 22. 
REYES, Italo. "Sobre la construcción de la exigencia de cuidado".

relevantes si no está en una posición actual de evitar un resultado lesivo ${ }^{104}$. Lo anterior no quiere decir que la incapacidad excluya la responsabilidad, pues si el autor sabe que ciertas conductas requieren de ciertas capacidades que actualmente no tiene y aún así ejecuta la conducta, entonces podrá existir imprudencia por asunción. Lo cuidadoso para el sujeto que advierte que carece de los requerimientos físicos o cognitivos para emprender una determinada actividad es no emprenderla: si lo hace y se genera un resultado lesivo, es responsable de un delito imprudente ${ }^{105}$.

En tal sentido, una postura individualizadora, lejos de ser injusta por conllevar una desigualdad de trato, pretende exigir a todos por igual. Si aplicamos un estándar fijo sin atender a los conocimientos y capacidades especiales, entonces se les exige lo mismo tanto a quienes pueden más como a quienes pueden menos. Ésa es la verdadera injusticia. Si aplicamos la misma exigencia de cuidado del sujeto que cuenta con capacidades promedio al que posee capacidades especiales superiores, entonces a éste último le exigimos menos que al primero, puesto que le resulta "un menor esfuerzo" cumplir con el estándar promedio. Así, si al médico de excelencia le exigimos lo mismo que al médico promedio, en definitiva, le estamos exigiendo menos. Si lo relevante es que todos los sujetos "den de sí" en forma equivalente, el estándar de cuidado no puede pensarse como una cantidad fija sino como un porcentaje: si la variable aumenta, manteniendo el mismo coeficiente, el producto también tiene que incrementarse. En otras palabras, si las capacidades y conocimientos aumentan, manteniendo el mismo estándar de cuidado, el nivel de exigencia también debe aumentar. Por tanto, para que la exigencia de cuidado sea justa debe construirse proporcionalmente según los conocimientos y capacidades del sujeto imputado. En palabras del sabio Ben Parker, en su lecho de muerte, a su (súper) sobrino, un gran (mayor) poder conlleva una gran (mayor) responsabilidad.

\subsection{3. ¿Comportamiento adecuado a rol?}

La última crítica justificaría la exclusión de conocimientos especiales por medio de afirmar que la víctima de un delito imprudente sólo tendría una pretensión legítima de ser protegida en la observación del cuidado adecuado a roles por parte de los demás ${ }^{106}$. Es decir, sólo existirían expectativas legítimas de comportamiento cuidadoso de acuerdo a la capacidad y conocimiento adecuado al rol que ejerce el autor. El argumento es tramposo porque se apoya en otro enteramente correcto: no es necesario obtener mayor capacidad y conocimiento que la que exige el rol específico a desempeñar. Ello tiene relación con la imprudencia por asunción, pues para que sea adecuado desempeñar una actividad, se exigen habilidades mínimas; de lo contrario, se exige su abstención. Por tanto, si se cumplen con

\footnotetext{
${ }^{104}$ KINDHÄUSER, El tipo subjetivo, cit. nota n ${ }^{\text {o }}$ 1, p. 22. Kindhäuser pone como ejemplo el médico que ha ingerido alcohol en un contexto social adecuado, el cual inhibe sus conocimientos y capacidades especiales por lo que, posteriormente, se ve incapacitado de auxiliar a un lesionado. En ese caso no existe actuar descuidado, porque actualmente - al momento del auxilio- carecía de esos conocimientos y capacidades especiales, independiente de que hubiese podido sin más prestar auxilio en caso de haber estado sobrio.

${ }^{105} \mathrm{Si}$ en el mismo ejemplo del médico alcoholizado, él sabe que un paciente requiere una intervención quirúrgica delicada y que no está en condiciones físicas de realizarla, lo cuidadoso es que no lo haga y que lo lleve a un hospital. Si lo opera y el paciente sufre alguna lesión, existe imprudencia por asunción.

${ }^{106}$ KINDHÄUSER, El tipo subjetivo, cit. nota n $^{\circ}$ 1, p. 22.
} 
Polít. crim. Vol. 10, No 19 (Julio 2015), Art. 3, pp. 56-91.

[http://www.politicacriminal.cl/Vol_10/n_19/Vol10N19A3.pdf]

los requerimientos mínimos que exige el desempeño de la actividad, resulta conforme a cuidado ejecutarla ${ }^{107}$.

Sin embargo, lo anterior no tiene ninguna relevancia respecto de quien se encuentra actualmente en posición de evitar un resultado dado su conocimiento o capacidad especial. $\mathrm{Si}$ el sujeto ya cuenta con los conocimientos o capacidades especiales, entonces se le exige conforme a ellos, dado que dispone del saber necesario para asegurar el seguimiento futuro de la norma. El rol que asume el autor no puede operar como una permisión a la realización de acciones contrarias a la exigencia de cuidado, pero sí tiene relevancia en la construcción del estándar, en cuanto a las expectativas de cuidado del sujeto. Porque el rol que ejerce el autor es uno de los elementos que deben tenerse en cuenta al momento de construir la exigencia de cuidado ya que las expectativas normativas de cuidado son diferentes en el desempeño de roles distintos ${ }^{108}$. En tal sentido, si el autor cambia de rol entonces también se ven alteradas esas expectativas modificándose el nivel de cuidado exigido ${ }^{109}$. Ello tiene que ver con que el ejercicio del rol requiere de ciertos conocimientos y capacidades que poseerá el integrante que se desenvuelve en ese ámbito. En otras palabras, el médico que actúa como médico (operando a un paciente) tiene ciertas capacidades comprometidas que determinan el cuidado exigido, pero si ese mismo médico actúa como mecánico carece de capacidades especiales en el rol que desempeña, de manera que las expectativas de su comportamiento deben verse afectadas.

De tal forma, el rol desempeñado no puede entenderse como el único elemento objetivo útil para determinar el nivel de cuidado, sino que es uno de los insumos que resulta relevante en la construcción. Que el autor desempeñe un determinado rol permite deducir las expectativas del ordenamiento para el comportamiento cuidadoso pertinente puesto que aquel ejercicio supone ciertas capacidades y conocimientos. No obstante, la referencia al rol no puede excluir la pregunta por lo que efectivamente podía y sabía el autor, y que definirá el cuidado debido bajo la irrenunciable pretensión de evitar una situación de incapacidad que hiciera inevitable la realización del hecho típico.

\section{Recapitulación.}

Si algo puede haber quedado claro con la presente investigación es que la manera en que el derecho penal determina si alguien se ha comportado descuidadamente es de todo menos unívoca: la dogmática de la imprudencia se ha desarrollado y sofisticado con especial fuerza desde el siglo pasado de una forma que esta exposición no alcanza a abordar completamente. Sin embargo el aparente complejo estudio jurídico penal de la imprudencia

\footnotetext{
${ }^{107}$ KINDHÄUSER, El tipo subjetivo, cit. nota $\mathrm{n}^{\mathrm{o}}$ 1, p. 23: "quien domina lo que el rol exige, domina lo suficiente como para poder participar en el sector del tráfico en cuestión. O formulado más precisamente: la incapacidad en lo que excede al rol no fundamenta responsabilidad por asunción alguna".

108 Éste es uno de los ámbitos más provechosos para una noción de riesgo permitido sistemáticamente coherente con la teoría aquí expuesta: los riesgos que puedan generarse por la no obtención de conocimientos o habilidades que exceden a las exigidas según el rol desempeñado son riesgos permitidos por el ordenamiento, pues no resulta razonable exigirle a un sujeto que controle todos los riesgos posibles, pues ello provocaría, en la mayoría de los casos, la imposibilidad de acción.

${ }^{109}$ KINDHÄUSER, ¿Qué es la imprudencia?, cit. nota ${ }^{\circ}$ 5, p. 224.
} 
REYES, Italo. "Sobre la construcción de la exigencia de cuidado".

no pretende sino determinar las condiciones bajo las cuales podemos afirmar que alguien debe responder penalmente a pesar de no haber estado, en el momento relevante, en posición de evitar la conducta típica. Ello implica construir un aparato conceptual que sea coherente con el modelo de imputación jurídico penal que pretende desentrañar la voluntad del agente objetivada en su conducta como contraria al ordenamiento.

En ese sentido, la imprudencia expresa la verdad de las "motivaciones" del agente: quien actúa descuidadamente no puede afirmar seriamente que se comporta con fidelidad a derecho pues sus acciones están demostrando precisamente lo contrario. De ahí que la construcción de la exigencia de cuidado evidencie una comparación entre el comportamiento de un sujeto preocupado por evitar situaciones en las que perderá el control del desenlace de su actuar y la conducta efectivamente realizada por el agente. Ello queda resuelto con la asunción de un estándar objetivo de cuidado que permite evaluar la conducta de cualquiera de modo equivalente. Pero si la figura de ciudadano responsable no está en la mismísima situación del sujeto en análisis entonces la comparación no puede conllevar un reproche en su contra. Y esa mismísima situación no sólo implica, por supuesto, el contexto específico en que se ejecuta el comportamiento sino también los conocimientos y habilidades especiales del sujeto que permiten dar cuenta con precisión de su capacidad comprometida en la situación respectiva. En definitiva, la exigencia de cuidado se concreta en una acción específica que un ciudadano fiel a derecho, con los conocimientos y habilidades especiales del sujeto, hubiese ejecutado (u omitido ejecutar) para asegurar su capacidad de evitación del comportamiento típico. 
Polít. crim. Vol. 10, № 19 (Julio 2015), Art. 3, pp. 56-91.

[http://www.politicacriminal.cl/Vol_10/n_19/Vol10N19A3.pdf]

\section{BIBLIOGRAFÍA}

BINDING, Karl, La culpabilidad en derecho penal, Montevideo/Buenos Aires: B de F, 2009.

BURKHARDT, Björn, "Conducta típica y perspectiva ex ante. A la vez, una aportación contra la confusión entre lo subjetivo y lo objetivo", en, WOLTER, Jürgen y FREUND, Georg (Eds.), Sistema integral de Derecho Penal, Barcelona: Marcial Pons, 2004.

CORCOY, Mirentxu, El delito imprudente, Montevideo/Buenos Aires: B de F, 2005.

CURY, Enrique, Derecho Penal, parte general, $7^{\mathrm{a}}$ Ed., Santiago: Ediciones Pontificia Universidad Católica, 2007, p. 333.

ETCHEBERRY, Alfredo, Derecho Penal, Tomo I, $3^{\text {a }}$ Ed., Santiago: Editorial Jurídica de Chile, 1998.

GARRIDO MONTT, Mario, Derecho Penal. Parte Especial, Tomo II, 4 ${ }^{\mathrm{a}}$ Ed. Santiago: Editorial Jurídica de Chile, 2005.

HART, H.L.A., "Negligence, mens rea and criminal responsibility", en: EL MISMO, Punishment and Responsibility, Oxford: Oxford University Press, 2008.

HERNÁNDEZ, Héctor, "Comentario al artículo 20", en: COUSO, Javier y HERNÁNDEZ, Héctor (Eds.), Código penal comentado, Santiago: Abeledo Perrot, 2011.

HRUSCHKA, Joachim, "La imputación ordinaria y extraordinaria en Pufendorf', en: EL MISMO, Imputación y Derecho Penal, Montevideo/Buenos Aires: B de F, 2009. "Reglas de comportamiento y reglas de imputación" en: EL MISMO, Imputación y Derecho Penal. Montevideo/Buenos Aires: B de F, 2009.

KINDH ÄUSER, Urs, “¿Qué es la imprudencia?”, en: MAÑALICH, Juan Pablo (Dir.), La ciencia penal en la Universidad de Chile. Libro homenaje a los profesores del departamento de ciencias penales de la facultad de Derecho de la Universidad de Chile, Santiago: Facultad de Derecho, Universidad de Chile, 2013.

KINDHÄUSER, Urs, "El tipo subjetivo en la construcción del delito", InDret 4/2008. , "El denominado riesgo no permitido", en: EL MISMO, Crítica a la teoría de la imputación objetiva y función del tipo subjetivo. Tres Estudios. Lima: Grijley, 2007.

MAÑALICH, Juan Pablo, "Norma e imputación como categorías del hecho punible", Revista de Estudios de la Justicia $\mathrm{n}^{\circ} 12$ (2010). , Norma, causalidad y acción, Madrid: Marcial Pons, 2014.

MARTÍNEZ, Marco, "La graduación del deber de cuidado en el delito culposo por actos de mala praxis médica: un análisis dogmático, jurisprudencial y económico", Política Criminal vol. 6, $\mathrm{n}^{\circ} 12$ (2011).

MOLINA, Fernando, "Dolo eventual e imprudencia con representación en los delitos de tránsito", Doctrina y jurisprudencia penal n 6 (2011).

MOORE, Michael, "Prima facie culpability", Boston University Law Review vol. 76 (1996).

NOVOA MONREAL, Eduardo, Curso de Derecho Penal Chileno, parte general, Tomo I,

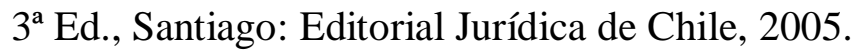

OVALLE, Germán, "Imprudencia y cognición", Doctrina y jurisprudencia penal n 4 (2011). 
REYES, Italo. "Sobre la construcción de la exigencia de cuidado".

PÉREZ DEL VALLE, Carlos, La imprudencia en el derecho penal. El tipo subjetivo del delito imprudente, Barcelona: Atelier, 2012.

RAGUÉS I VALLES, Ramón, El dolo y su prueba en el proceso penal, Barcelona: Bosch Editor, 1999.

ROJAS, Luis Emilio, "Lo subjetivo en el juicio de imputación objetiva: ¿Aporía teórica?”, Revista de Derecho U. Austral vol. XXIII, n¹ (2010).

ROSAS, Juan Ignacio, "La delimitación del deber de cuidado en la imputación de responsabilidad penal por imprudencia médica", Doctrina y jurisprudencia penal $\mathrm{n}^{\circ} 5$ (2011).

ROXIN, Claus, Derecho Penal, parte general. Tomo I. Madrid: Civitas, 1997.

TORÍO LÓPEZ, Ángel, "Sobre los límites de la ejecución por imprudencia", Anuario de derecho penal y ciencias penales, tomo XXV (1972)

, "El deber objetivo de cuidado en los delitos culposos", Anuario de derecho penal y ciencias penales, tomo XXVII (1974)

VAN WEEZEL, Álex, "Parámetros para el enjuiciamiento de la infracción al deber de cuidado en los delitos imprudentes“, Revista Chilena de Derecho, vol. 26, $\mathrm{N}^{\circ} 2$ (1999).

VON WRIGHT, Georg Henrik, Norma y acción, Madrid: Editorial Tecnos, 1970.

ZUGALDÍA, José Miguel, "La infracción del deber individual de cuidado en el sistema del delito culposo", Anuario de derecho penal y ciencias penales, tomo XXXVII, fascículo II (1984). 